\title{
Overlapping talk and the organization of turn-taking for conversation
}

\author{
EM A N UEL A. SCHEGLOFF \\ Department of Sociology \\ University of California \\ Los Angeles, CA 90095-1551 \\ scheglof@soc.ucla.edu
}

\section{A B S T R AC T}

This article provides an empirically grounded account of what happens when more persons than one talk at once in conversation. It undertakes to specify when such occurrences are problematic for the participants, and for the organization of interaction; what the features of such overlapping talk are; and what constraints an account of overlapping talk should meet. It describes the practices employed by participants to deal with such simultaneous talk, and how they form an organization of practices which is related to the turntaking organization previously described by Sacks et al. 1974. This “overlap resolution device" constitutes a previously unexplicated component of that turn-taking organization, and one that provides solutions to underspecified features of the previous account. (Conversation analysis, turn-taking, overlap, interruption, interaction, prosody.)*

The orderly distribution of opportunities to participate in social interaction is one of the most fundamental preconditions for viable social organization. For humans, conversation and other more specialized or context-specific forms of talkin-interaction (such as debate, interview, courtoom talk in session, ritual etc.) are species-distinctive embodiments of this primordial site of sociality.

One feature that underlies the orderly distribution of opportunities to participate in conversation, and of virtually all forms of talk-in-interaction that have been subjected to disciplined empirical investigation, is a turn-taking organization. This is an organization of practices designed to allow routine achievement of what appears to be overwhelmingly the most common default "numerical" value of speakership in talk-in-interaction: one party talking at a time. This is a matter not so much of politeness as of the constitutive features of commonplace talk-ininteraction, as an enabling institution for orderly commerce between people. (Of course, systems of etiquette are commonly found in societies as a social control resource to motivate and reinforce compliance.) The absence of such an organization would subvert the possibility of stable trajectories of action and responsive action through which goal-oriented projects can be launched and pursued through talk in interaction, whether to success or failure (Schegloff 1988:98-99). 
The organization of turn-taking practices in talk-in-interaction is among those features of social life that are so deeply embedded in ordinary common-sense practice that they challenge articulate awareness and explicit, disciplined description. Although this feature was registered informally by Goffman as early as 1955, and explored on a limited range of interactional formats (i.e. two-person interactions) by Duncan and his associates $(1972,1974,1977)$, the main account offered in the social sciences has been that of Sacks, Schegloff \& Jefferson 1974 (henceforth SSJ). That account took, as a central problematic for turn-taking in conversation, an organizational device that would allow parties to achieve the design feature of one-party-at-a-time in the face of a recurrent change in who the speaking party was, while providing as well for such occasions of multiple speakership and lapses in the talk (i.e. silence) as the parties might undertake to co-construct.

This article aims to provide an empirically grounded account of what happens when more than one person talk at once in conversation; of how the practices mobilized for such simultaneous talk are organized; of how they are related to the turn-taking organization previously described in SSJ, and constitute a previously unexplicated component of that turn-taking organization; and of how they provide solutions to previously underspecified features of the previous account. These matters are taken up in that order.

For students of conversation and other talk-in-interaction, what is promised is a depiction of a set of practices which make up a critical part of the social organization of turn-taking, and are key to the management of a type of conflict endemic to talk-in-interaction. For those in any discipline who seek analytic tools for the detailed examination of real-world talk-in-interaction, suitable for the analysis of actual singular episodes of talk, it offers tools for dealing with overlap and its environment. For those interested in "interruption" as a signal event in interaction - one with rich interpretive and analytic implications for social and cultural analysis - it offers analytic resources that lie near the heart of the phenomenon; however, the treatment of "interruption" itself is deferred to another occasion.

\section{P R O LE G O M E N A}

Talk by more than one person at a time in the same conversation is one of the two major departures that occur from what appears to be a basic design feature of conversation, and of talk-in-interaction more generally, namely "one at a time" (the other departure is silence, i.e. fewer than one at a time). ${ }^{1}$

To take "one-at-a-time" to be a basic design feature in participants' coconstruction of talk-in-interaction is not to assert that it is invariably achieved. If some design feature of ANY project, pursued through an organization of practices, fails to be achieved on some occasion (or even on many occasions), this is not prima facie evidence that it is not a design feature to which participants orient in the course of its production. Nevertheless, it is clear from the most 
cursory examination of the data of talk-in-interaction (as well as the most CAREFUL examination of such data) that, overwhelmingly, "one-party-at-a-time" IS achieved.

Comparison with activities that are designed to implement other values of " $n$-at-a-time" (such as "all-at-a-time" in collective chanting or cheering in political or athletic venues, ${ }^{2}$ or congregational responses in religious services), or with those that are not organized at all in this respect (e.g. the multiple conversations simultaneously in progress at parties, yielding the hubbub known as the "cocktail party phenomenon"), allows a ready appreciation of what a different sound talk-in-interaction has by virtue of its one-party-at-a-time design, whether it is conversation or some more specialized and context-specific speech-exchange system. This is so across all the occasionally claimed proclivities of members of various social categories - ethnic, gender, class, or cultural - to depart from this feature. No matter how much overlapping may be found in the talk of members of such categories (even granting the relevance of this categorical identification), the talk appears to be co-constructed by reference to one-party-at-a-time as its targeted design feature, ${ }^{3}$ rather than to any other value, or no value at all. The evidence for this is not only in the aggregate achievement of masses of conversational and other interactional data. It is to be found as well in what is done by parties to talk-in-interaction in the presence of a departure from this normative feature in the organization of talk-in-interaction.

However simultaneous talk comes into being - whether by simultaneous startups of a next turn by more than a single speaker, or by apparently orderly and warrantable start-ups by a next speaker while a prior is still talking (cf. SSJ 1974:721, Jefferson 1984a, Lerner 1991, 1996), or by outright interruptions (whether designed or not) - the issue that the present discussion addresses is how they are managed by the participants once they occur. Is there some sort of device for the management of overlap - some organized set of practices by which overlap gets resolved by the parties, or fails to get resolved?

It appears that the device for managing overlap, i.e. the practices by which a trajectory to resolution is produced, is independent of the mode of onset of the overlap, in whatever terms that onset may be described. The account offered in this essay is grounded in this premise, and the terms of analysis that are its product - the account of practices of talking in overlap - may in turn be employed to reexamine the premise. Accordingly, in most of the following discussion I will refer to "overlap" or "simultaneous talk," and I will eschew references to "interruption" - a term whose service as an analytic resource is beset by serious problems, and one whose relation to overlap and turn-taking I will take up elsewhere. This is not to deny the robustness of "interruption" as a vernacular term, and as an experience. Nor is it to deny that the onset of a particular episode of simultaneous talk, and the decision whether it is taken to be an interruption (by either party, the prior speaker or new starter), may figure in how the parties conduct themselves in dealing with that instance of simultaneous talk. The premise here is that THE 
ORGANIZATION OF PRACTICES FOR MANAGING OVERLAPPING TALK IS INSENSITIVE TO THE MODE OF THE OVERLAP'S ONSET, and not that the practices adopted by the parties and the manner of their deployment on any given occasion are insensitive to it.

The most obvious practice for stopping talk by more than one at a time is to stop talking. One or more of the parties to the simultaneous talk should stop talking; and to display that it is the overlapping talk that is the grounds for stopping, they should stop talking before coming to a possible completion of the turn-constructional unit they are producing. But which one should stop? Aye, there's the rub! That is part of what an overlap management device is about. All that is wanted for and by the organization of interaction is that the overlap should stop; organizationally speaking, it is a matter of indifference who withdraws. But the parties may care very much indeed ... or not. An overlap management device, or an overlap resolution device, provides the resources and the practices with which the parties can reconcile the requirements of the organization of interaction with the projects and courses of action in which they are severally engaged at that very moment. It is this organization that I aim to describe. ${ }^{4}$

The points to which I will draw attention in this introductory discussion are considerations preliminary to a systematic account of how simultaneous or overlapping talk is managed in talk-in-interaction - preliminary, that is, to a model of an "overlap-resolution device." 5

\section{Exclusions from the domain of an overlap resolution device}

One important set of preliminary considerations concerns the sort of materials for which an account should (and should not) in the first instance be built and be adequate, and the sorts of materials that can properly be taken to exemplify the general case.

As a first step in taking up that question, I want to exclude from the materials relevant to my concerns here certain types of episodes of overlapping talk primarily those types in which the simultaneous speakers do not appear to be contesting or even alternative claimants for a turn space. In these cases, the conduct of the participants does not show these occurrences to be taken as problematic by them, and this feature governs their treatment by us as analysts. There are four types of occurrences in which simultaneous talk does not appear to be "problematic" with respect to turn-taking.

Before characterizing these, however, it is useful to reiterate a sometimes neglected, though obviously critical, aspect of the "one-speaker-at-a-time" provision, namely that it operates for single conversations: "one speaker at a time in a single conversation." It follows that one large class of occurrences that are outside the scope of the present undertaking - but do not properly merit the characterization "exclusions," since they do not belong there in the first place - is that of simultaneous talk by speakers who are participants in separate but ecologically near conversations (or other forms of talk-in-interaction). 
Parties to a conversation can be demonstrably sensitive to events in their environment or setting, including talk in other conversations within earshot. Furthermore, they can display overtly, in their talk or other conduct, an orientation to talk that is simultaneous with their own and whose origin is not in their conversation (and that is not subsequently incorporated in it - i.e. is not the vehicle for entry to it). Still, these are ordinarily treated as events in the ENVIRONMENT of the conversation, and even if competitive WITH it (e.g. via volume that drowns it out), they are not competitive WITHIN it. The present account is directed to talk by more than one speaker in the same conversation, which is the locus for the "onespeaker-at-a-time" provision in the first instance.

Similarly, simultaneous talk within a single conversation can, under some circumstances (e.g. when there are four or more participants in the conversation), engender the schisming of that conversation into multiple conversations (SSJ, 713-14; Egbert 1993, 1997), in each of which "one-speaker-at-a-time" then pertains. For as long as the overlapping talk continues to be oriented to recipients treated as members of the same single conversation, it is of course a proper part of the universe being addressed in this essay. Once the overlap has been "resolved" by the schisming of the conversation into multiple conversations, the same simultaneously speaking voices no longer belong to that universe.

That said, we return to four types of overlapping talk that appear in the first instance not to be relevant occurrences for an overlap management device.

First, there are "terminal overlaps" in which one speaker appears to be starting up by virtue of a prior speaker's analyzably incipient finishing of a turn. Here the very auspices under which the overlap comes into being project its almost immediate self-liquidation, as the incipiently finishing speaker brings the prior turn to completion (although this outcome is not inevitable; cf. Jefferson 1984a, 1986). This projected self-liquidating feature obviates the need for special practices for managing the overlap.

Second are "continuers" (i.e. interpolations such as $u h \mathrm{huh}, \mathrm{mm} \mathrm{hm}$, contextfitted assessment terms etc.; cf. Schegloff 1982, C. Goodwin 1986), by which recipients of another's talk can show precisely that they understand that the speaker is in the course of an extended turn at talk which is not yet complete. Such continuers are specifically ALTERNATIVE to an independent and competitive spate of talking - here excluding, therefore, the shift-implicative tokens, i.e. those whose deployment can serve notice that their speaker means to move to assume speakership (cf. Jefferson 1984b). Thus continuers do not mobilize special practices for the management of simultaneous talk.

Third, there are various phenomena that can be collected under the rubric "conditional access to the turn," in which a speaker of a not possibly completed turn-in-progress yields to another, or even invites another to speak in his turn's space, conditional on the other's use of that opportunity to further the initial speaker's undertaking. The most familiar instances are (a) the word search, in which a recipient may be invited to participate in finding a word (e.g. a name) that 
the current speaker-of-record cannot retrieve; and (b) collaborative utterance construction, in which one participant initiates an utterance and provides for another to complete it. Both these phenomena, initially identified as research topics by Sacks 1992, have been recently made the topics of penetrating accounts, the former by M. Goodwin \& C. Goodwin 1986 and the latter by Lerner 1987, 1991, 1996. Again, in each case, if the initial and subsequent speakers end up talking at once, this is generally (though not invariably, cf. below) treated by them as noncompetitive and non-problematic (cf. also Tannen 1983).

Fourth, I wish to exclude that set of forms of talk which we can refer to as "chordal" or "choral" in character. Here I mean to call attention to forms of talk and activity that are treated by interactional co-participants as NOT to be done serially, not one AFTER the other, but to be done simultaneously. The first is laughter, whose occurrence (as Jefferson 1979 has shown) can serve as an invitation for others to laugh, but whose elicited product is done in concert with other laughter, not after it. Otherwise, there are activities such as collective greetings, leave-takings, and congratulations in response to announcements of personal good news. Such activities in multi-person settings are regularly produced "chordally," not serially; and the chordal production is done and heard as convergent and consensual, not competitive. ${ }^{6}$ Here again, as in all the classes of occurrence that I mean to exclude from this discussion, the several overlapping participants do not appear to be, or to conduct themselves as, alternatives or competitors, but rather as properly simultaneous occupants of the floor - either as a permissible matter (e.g. with overlapping continuers) or as a mandated one (e.g. in choral congratulations). In contexts like these, "management of overlap" may be best understood not as overlap RESOLUTION, but as the orderly practice of producing what will count as appropriate simultaneous production. ${ }^{7}$ Accordingly, such occurrences are not IN THE FIRST INSTANCE apt material for an account of overlap resolution.

It is worth underscoring that the "exemption" for these classes of overlapping talk pertains ONLY IN THE FIRST INSTANCE, i.e. for developing a first-order account. Then, with an account of overlap resolution practices in place, we can lift the "exemption" and note that some candidate "unproblematic" overlaps turn out to have overlap-resolution practices deployed by one or more of the parties; this may show the parties to be treating what could have been an unproblematic overlap (e.g. an incipiently "terminal" overlap) as "problematic on this occasion." That is, even though generically that kind of activity is NOT competitive or problematic, on a given occasion it MAY BE problematic - for those parties, at that moment, given what they are doing and have been doing - in which case they can draw on the practices of overlap management to be described below.

Apart from such licensed or mandated productions of simultaneous talk, ${ }^{8}$ practices for the MANAGEMENT of overlapping talk ordinarily amount to practices for the RESOLUTION of overlapping talk. The remainder of this article, therefore, can best be understood as the depiction of an overlap resolution device deployed by 
parties to talk-in-interaction, and as an integral component of the turn-taking organization for conversation, and for other speech-exchange systems that have overlap as a provided-for contingency.

\section{Specification of "more than one at a time"}

"Overlap" refers to talk by "more than one at a time." In the materials drawn from ordinary talk-in-interaction with which I am familiar, it turns out with great regularity that, when more than one person is talking at a time, Two persons are talking at a time, and not more; this appears to be invariant to the number of participants in the interaction. ${ }^{9}$ Talk by MORE than two at a time seems to be reduced to two (or to one) even more effectively than talk by two is reduced to one. In part this occurs because the vast majority of instances of three talking at a time involve two speakers who simultaneously start next turns in terminal overlap with the incipient turn completion of a third, whose actual completion accomplishes the reduction. ${ }^{10}$

When simultaneous talk by more than two develops which is not self-liquidating in this sense, it appears to be engendered by the type of interactional contingency exemplified by the following extract. (A glossary of most symbols used in the transcript extracts may be found in Appendix 1. See the end of note 10 above for directions on accessing the sound for the data extracts in this paper.)

(1) Post-Party, 7

1 Marty: Ih w'z a liddle well done.

2 Fred: Uhm,

3 Anne: Oh[: I s]aw] a] 1:lot'v ra:re pieces.

4 Fred: [I[t w'z $] \mathrm{fi}]:$ ne $]$.

5 Marty: [Ih w'za-]Ih-] Ih] w'z a fanta:stic piece a' meat.

In the car on the way home from an extended-family party, a discussion is in progress about the party. Marty has described the main course as a very good roast; but when his wife characterizes it as a little overdone, Anne does not quite hear her and asks for a repeat. When Marty repeats this negative assessment (at 1:1) on his wife's behalf, in response to Anne's request, Fred and Anne both come to the defense of the roast (and its cook); and the early indications that they are doing so (Fred's uhm at 1:2 and Anne's oh at line 3) prompt an immediate backdown by Marty (at 1:5) to what had in any case been his original evaluation.

Note, then, that Marty's start-up is a preemptive response to simultaneous incipient disagreements voiced by two interlocutors to his prior utterance; there is thus a serious possibility of three turns being launched more or less simultaneously, with the prospect of sustained (rather than self-liquidating) overlap. It is this sort of context that engenders the possibility of serious (i.e. sustained and competitive) simultaneous talk by MORE than two, seeking to occupy the same turn space. But even here, Marty several times cuts off and restarts his backdown turn, until one of his competitors, Fred, brings his disagreeing turn to completion; 
as a result, the sustained overlap that ensues involves just Two overlapping turns and speakers, not three.

\section{Forms of overlap configuration}

As just noted, "more than one at a time" ordinarily involves two at a time. There are just three configurations that overlapping talk by two speakers can take, characterized schematically as follows:

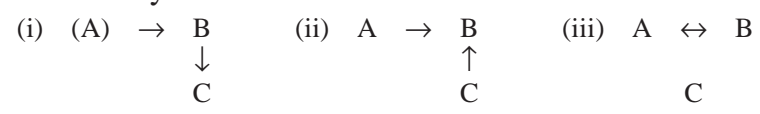

In (i), A is talking to B, and B is talking to C. In (ii), A is talking to B and C is talking to B. In (iii), A is talking to B and B is talking to A. I will offer only a few observations about these configurations of simultaneous talk.

The first observation (the product more of casual though careful observation than of systematic analysis of video materials) is that deployment of the body, and especially gaze direction, appears to figure differently among the three. In configuration (ii), the gaze direction of B is likely to feature centrally. A and C can be understood to be competing for THIS recipient, namely B, and gaze direction can be an indication of which competitor this recipient is favoring. Commonly, if $\mathrm{B}$ directs gaze at $\mathrm{A}$, then $\mathrm{C}$ will drop out of the competition, and $\mathrm{B}$ can thereby be understood to have decided the matter. But on occasion, $\mathrm{C}$ can respond by competing for the recipient more vigorously - talking louder, at a higher pitch etc. Although almost certainly the body can be deployed in a manner relevant to overlap in configuration (iii), it does not appear to figure so centrally in that circumstance.

A second observation is that, although these appear to be three discrete and different configurations of overlapping talk, (i) and (ii) can naturally alternate under the operation of the turn-taking system. Begin with configuration (i): A is talking to B, and B is talking to C. One "natural" next phase is that, on possible completion of B's turn, C properly responds to B. If C does so, then configuration (ii) is brought into existence: $\mathrm{A}$ is talking to $\mathrm{B}$, and $\mathrm{C}$ is talking to $\mathrm{B}$. When $\mathrm{C}$ comes to a possible completion, $\mathrm{B}$ may appropriately address $\mathrm{C}$ again, and configuration (i) is again brought into existence. These two configurations are, in that sense, natural alternators.

Lest this be thought a merely theoretical, logically generated possibility, let me hasten to provide an instance of the sort of empirical material it is meant to characterize. The material in extract 2 was recorded in a used-furniture store in New York City about 25 years ago. Mike works in the store; Vic and James are janitor/custodians in nearby apartment houses. Earlier in the day, a window was broken in James's building while he was away. Mike found out about it and told Vic, who cleaned up the broken glass, and encountered the likely culprit while doing so. Upon James's return, the story of the incident is told and retold. James has asked Vic for help in identifying the culprit several times, and Vic has several 
times agreed to give such help; and Vic recurrently seeks credit for cleaning up and encountering the likely perpetrator. ${ }^{11}$

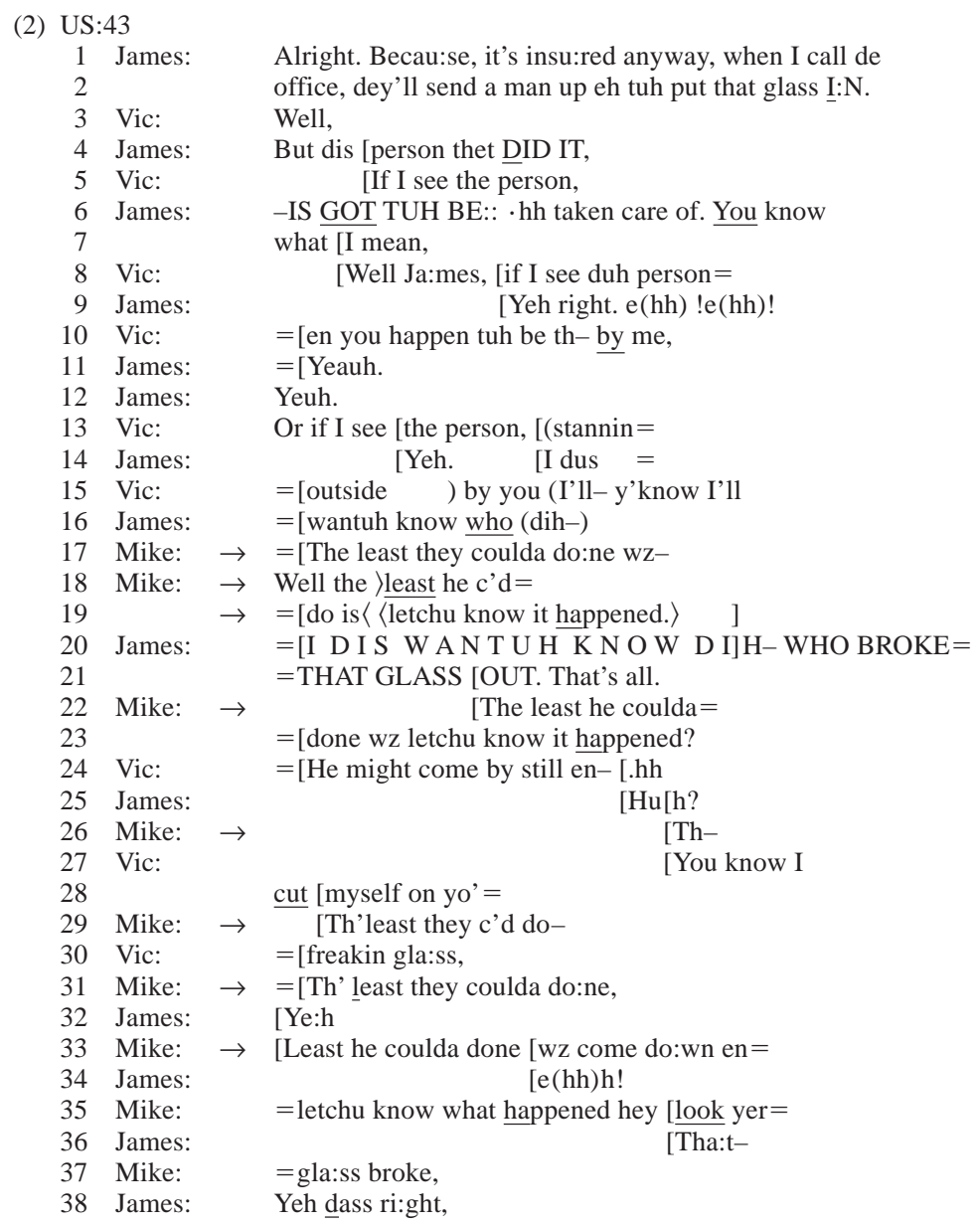

Seven times Mike tries to say his piece (marked by the arrows at 2:17, 18-19, 22-23, 26, 29, 31, and 33-35-37). Four of these tries are abandoned before possible completion, as Mike finds himself talking simultaneously with another. The tries initiated at 2:18 and 2:22 are pressed to completion; but in each case Mike finds them ineffective, i.e. not sequentially implicative or consequential, by virtue of their involvement in overlap. Only the last try, starting at 2:33, is said substantially in the clear, and is acknowledged by a recipient.

Let us identify Mike with "A" in our patterns of overlap, and James (who is the you of Mike's The least they could have done is let You know it happened) with "B". At Mike's tries at 2:17 and 2:18-19, James is talking to Vic (B is talking to 
$\mathrm{C}$ ); at the try at line 22, Vic is responding to James ( $\mathrm{C}$ is talking to $\mathrm{B}$ ). At the tries at 2:26, 2:29, and 2:31, Vic is talking to James as Mike is also addressing James ( $\mathrm{C}$ to $\mathrm{B}, \mathrm{A}$ to $\mathrm{B}$ ); and in the try at $2: 33$, James is responding to Vic.

So we have here just the circumstance previously described schematically. There is a colloquy in progress between B and C - here James and Vic - into which A, here Mike, is trying to break. These two configurations, (i) and (ii), alternate as A's repeated efforts to gain $\mathrm{B}$ as a recipient run into an alternation in the conversation between $\mathrm{B}$ and $\mathrm{C}$.

Of course, it is unusual to find as extended a series of efforts as this, which displays so clearly the alternation of these two configurations - which shows them to be alternate "values" of a single form of organization. It allows us to appreciate that much briefer episodes, in which either configuration (i) or (ii) is observed, are moments caught in a potential stream of conduct which has this potential trajectory, but which the involved parties ordinarily arrest before it gets to this point. The competition for B's gaze, which I remarked on earlier, can thus be seen to have a history and/or a future; it will be enmeshed in an ongoing or prospective effort to prevent a colloquy from forming, or to intervene in one already in progress.

Clearly, occurrences like those described by configurations (i) and (ii) are NOT THE GENERAL cases of overlap. For one thing, they necessarily involve three participants. If we want to understand in the most general way how simultaneous talk comes to occur and how it is resolved, we should examine occurrences structured like configuration (iii). This requires for its occurrence only what talk-in-interaction per se appears to require: two participants, which is the number who generally are talking if more than one is talking. It is surely possible that two participants will deal with their overlapping talk to each other differently, depending on whether there are other ratified co-participants, or whether those two are the only present company. But it does appear that the practices of conduct by which overlapping speakers deal with their simultaneous talk are formed in the first place to deal with talk by two, to each other. If things are different when more are present, this seems to involve modifications to those practices. ${ }^{12}$

\section{Constraints on an overlap resolution device}

Our treatment of overlap and its resolution in conversation (and eventually in other speech-exchange systems) should be able to come to terms with, and to elucidate, several grossly apparent observations about overlaps taken in the aggregate:

(a) Most overlaps are over very quickly.

(b) Some overlaps persist to considerable length.

(c) Many overlaps are the site of hitches and perturbations in the production of the talk. 
Of course, "overlap" as a class of occurrences is composed of many separate events, in each of which more than one person is talking at a time in the same conversation. Accordingly:

(d) A satisfactory discussion of the management of overlap by participants in talk-in-interaction should provide an account of the treatment of singular, individual occasions of overlap by the participants, and at the same time should be compatible with (and illuminate) observations about the aggregate of overlaps such as those formulated above.

As noted earlier, overlap is a recognizable event IN THE FIRST INSTANCE by reference to a turn-taking organization. The possible relevance of noting that talk is being produced by more than one at a time is underwritten by the otherwise oriented-to feature of one-at-a-time, and the omnirelevant organization for implementing that feature as an achievement. Accordingly:

(e) Because the production, registering, and management of overlap involve some special facets of turn-taking, dealing with overlap should also be systematically related to the rest of the turn-taking organization.

(f) Just as the turn-taking organization as a whole is part of an infrastructure through which other interactional interests and preoccupations may be pursued, so should the management of overlap resolve turn-taking anomalies, and also accommodate non-turn-taking interactional interests that may get embodied in turn-taking terms.

(g) More generally, an account of practices for the treatment of overlap should be compatible with the account already in hand of the turn-taking organization for conversation: party-administered, locally deployed, and managed in a recipientdesigned and interactionally sensitive manner (SSJ, 724-27).

\section{AN OVERLAP RESOLUTION DEVICE}

The overlap resolution device at work in conversation is composed of (a) a set of resources of turn production; (b) a set of places at which those resources get deployed; (c) and an interactional "logic" by which those resources, in those places, constitute "moves" of a describable sort in a competitive sequential topography.

\section{Resources: Hitches and perturbations}

I noted before that stretches of overlapping talk are characterized by hitches and perturbations in the talk. By that I mean deflections in the production of the talk from the trajectory which it had been projected to follow. These can then be momentary arrests in the continuity or "progressivity" (Schegloff 1979) of the talk's production - what I call "hitches" - or marked departures from the prosodic character of the talk's articulation to that point - what I call "perturbations." Few of these hitches and perturbations are entirely absent from other talk-in-interaction. 
It is their especially dense occurrence and the "strategic" import of their occurrence in overlapping talk that we are taking note of here.

What, then, are these hitches and perturbations? The talk can get suddenly (i) louder in volume, (ii) higher in pitch, or (iii) faster or slower in pace, depending on where in the overlapping talk the change in pace occurs (more on this below). The talk-in-progress may be (iv) suddenly cut off, most commonly with what linguists call a glottal, labial, dental, or some other oral stop; ${ }^{13}$ or (v) some next sound may be markedly prolonged or stretched out; or (vi) a just prior element may be repeated. Several of these deflections from the "normal" course of production may be combined, as when a speaker repeatedly cuts off a word or phrase in progress and then repeats it, only to cut off the repeat at the same point and redo the entire operation - resulting in a spinning-one's-wheels effect. ${ }^{14}$

Some of these hitches and perturbations invite understanding, even in commonsense terms, as forms of strategic maneuver in a competitive or agonistic undertaking - a fight for the floor, in which talking louder may aim to "shout the other down," and to win by a show of acoustic force. But others of these deflections in the production of the talk may appear rather more as casualties of the conflict than as weapons in it. For example, self-interruptions may appear to be at least momentary surrenders in the face of competition. Sound stretches may be taken as interferences in the production of the talk, induced by a kind of processing overload which is imposed by the simultaneous tasks of speech perception and production, with the former somehow interfering with the latter.

However, when we examine the distribution of these hitches and perturbations in the developing course of overlapping talk, we may come to understand all the deflections as possible resources deployed by speakers in managing the course and resolution of the overlap, and of their position within it. Consider the following:

(3) TG, 14:36-43

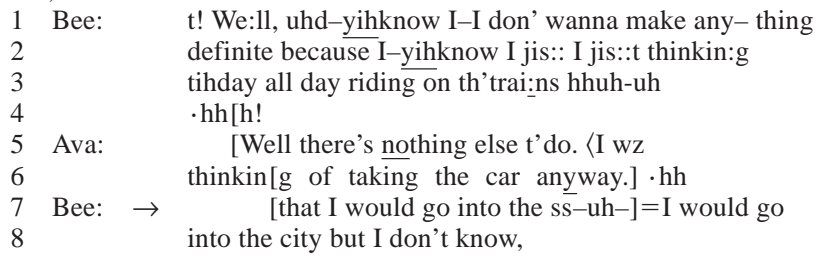

Ava has been trying to entice Bee to join her the next day when she travels from Long Island into Manhattan. Bee has been resisting, and is resisting again at $3: 1-4$, being in the course of retracting the possible plan of going into the city which has elicited Ava's efforts. At 3:5-6, Ava presses the talk through the end of one turn unit (nothing else t'do) into the start of another ( $I$ wz thinking), engendering an overlap when Bee (at 3:7) voices the ostensible continuation of the talk which she was producing at 3:3-4. Then note that the talk proceeds fluently on both their parts, until there is an apparent hitch in Bee's turn in the phrase into the 
c [ity]. The initial consonant of city is stretched and then cut off (represented in the transcript as $s s-u h-$ ), before the whole is recycled from the start of the clause.

Note, however, where this hitch occurs. As the alignment of the transcript roughly shows, at just this point Ava is producing the word anyway, which her turn-so-far, in its sequential position and with its interactional import (i.e. "in context"), projects as the turn's possible completion. Thus Bee can hear that Ava is about to come to the possible completion of her turn-constructional unit and, with it, of her turn. Bee's sound stretch at just that point allows her to avoid finishing earlier or simultaneously; it "absorbs," so to speak, the remainder of Ava's overlapping talk, allowing Bee to emerge "into the clear," and, once there, to re-say her utterance free of potential impairment by simultaneous talk. At just the point where her interlocutor's talk ends, the hitch ends as well; so the utterancein-progress is recycled and re-said in the clear. This instance of sound stretch thus appears to be more weapon than casualty - more a deployed resource than an overloaded perceptual/cognitive apparatus, especially given the undisturbed texture of the talk in the overlap to that point. (See further discussion in Schegloff 1987a and convergent findings in French \& Local 1983; and cf. C. Goodwin 1981:127-29, who describes the use of sound stretches to prolong a segment of talk until the arrival of recipient gaze.)

We can see the same resources at work here:

(4) Pre-Party, 12

1 Deb: How [come you get thiz:: thi:s v::::::]ersion of ] jovial

2 Anne: [W'd you please concentrate on drivi]ng the ca:r,]

In the turn just preceding, Dick, who is driving the family to a party, has made a pun; his wife (Anne) and adult daughter (Deb) are responding with one common mode of response to puns, i.e. disdain. They do so simultaneously, Anne's retort coming out "fluently" and Deb's with hitches. Note where the hitches in Deb's turn occur. The first occurs on the word thiz::, produced as Anne is beginning the word concentrate, on whose completion her turn could be possibly complete. Deb recycles the word as the final syllable of concentrate is due; but then she finds that Anne's turn is not in fact over, and that concentrate is being given a grammatical complement. Deb then imposes an extraordinary sound stretch on the initial consonant of the next word of her turn - the $v$ of version. She holds that $v$ until just before the next possible completion of Anne's overlapping talk, projecting its completion at concentrate on driving. As driving is coming to an end, she releases the sound stretch on the $v$ into the remainder of version of jovial, which turns out to be still overlapping with a yet further extension of Anne's turn. Nonetheless, the position of Deb's sound stretches again appears to be more a strategic placement than a subverted production.

A final instance displays that both parties to an overlap may play the same game, and at the same time. In ex. 5, Deb and Anne are involved in a somewhat heated disagreement as to whether or not Deb had received a trousseau when she 
got married. She has asked why she did not, and Anne has challenged that premise. Deb is backing away from her complaint:

(5) Pre-Party, 6

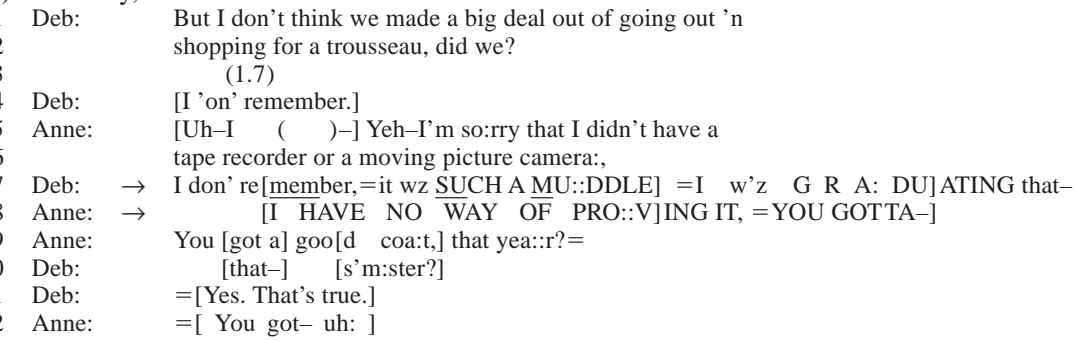

Focus on the action at 5:7-8. Deb is offering an account that her preoccupations at the time of her wedding have clouded her memory, and this account is developed over three turn-constructional units (TCUs). At the same time, Anne is undertaking to document her claims about the trousseau, at this point occupying two TCUs. As they approach possible completion of the units that are overlapping, each can hear that the other is coming to possible completion. As Anne is starting proving it (with a continuation likely already in the works), she can hear Deb starting the word muddle, which will constitute possible turn completion. Deb, on the other hand, as she starts muddle, can hear Anne hovering at the turn completion projected by the turn-so-far, I have no way of ... Note then that the next component of each turn becomes the site of a sound stretch which can absorb the projectable remainder of the other's TCU and turn. As it happens, these sound stretches cancel each other out. Each speaker rushes through (Schegloff 1982) the juncture following her possible completion into a next TCU, where they find themselves, still and again, in simultaneous talk - which they continue to manage, but with different resources. Here again, we can see the sound stretch not as a toll exacted by overloaded speech production and reception systems, but rather as a deployable resource, mobilized to do a determinate job at a determinate place in an ongoing positional conflict. ${ }^{15}$

What is that place? How shall we characterize the position at which these sound stretches are deployed? In the course of tracking these three episodes, we have already noted a characterization. These sound stretches have been deployed when the other speaker's overlapping talk has appeared to be on the point of coming to possible completion, yielding a projectable resolution of the overlap. It is the prospect of imminent "natural" overlap resolution - i.e. by one utterance coming to closure, rather than being prematurely ended - that prompts deployment of the sound stretch to "absorb" the overlap remaining before projectable resolution. We might then term this practice a "pre-resolution stretch."

But in doing so, and in view of the grounds we have developed for doing so, we should note that we have in effect been recognizing a distinct "place" or 
"phase" in the developmental course of an overlap. Because we have been led to this by tracking the place where a distinctive practice is deployed by the participants, the phase we have formulated offers itself not as an external analyst's imposition, but as an indigenous aspect of the participants' understanding of the organization of overlapping talk. The trajectory of an overlap, it appears, can have phases for the participants, and these can be relevant to the type of conduct they deploy. It is to an elucidation of these phases that we turn next.

\section{Places: Phases of an overlap}

One might think that the first phase of an overlap begins with the onset of simultaneous talk, but this is not necessarily the case. Rather, parties to talk-ininteraction may be oriented to what we will term the PRE-ONSET PHASE of an overlap. That is, a speaker of a turn already in progress may detect - either from body behavioral displays (such as postural realignment or gesture deployment) or from other common turn-pre-beginning practices, such as pre-turn hearable inbreath (Schegloff 1996a) - that another is about to launch a turn. ${ }^{16}$ Such an alreadyspeaking speaker may deploy the practices otherwise available for dealing with overlapping talk to address the prospect of incipiently overlapping talk, and possibly to interdict it, in this "pre-onset" phase. Ex. 6 reproduces the start of ex. 2 above:

(6) Upholstery Shop, 43

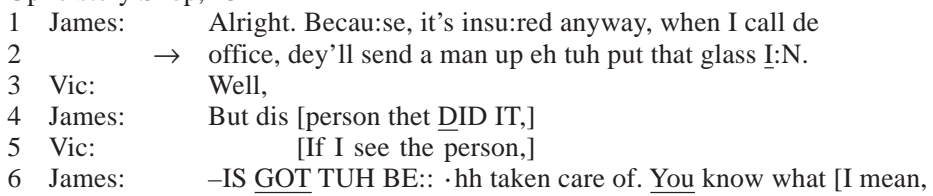

At 6:1-2, James is setting aside concerns about the cost of the broken window in favor of settling up with the culprit; and as he comes to the possible completion of one of the TCUs that compose his turn, he apparently registers Vic's gearing up to start a turn of his own (the turn that is actually started a moment later at line 3 ). James seeks to interdict that start-up with a sudden sharp increase in the volume (and pitch) of his talk, represented in the transcript by the capitalization and partial underlining of the word $I: N$ on line $2 .{ }^{17}$ This effort fails to head off Vic's talk, which is launched directly after it.

Other practices besides sharply increased volume can be deployed in the preonset position. Ex. 7, already examined in another connection (see ex. 2 above), comes from another round of discussion of the broken window, in which Mike is trying to convey the view that the culprit ought at least to have informed someone of what had taken place, while James reasserts his abiding interest in establishing the identity of the culprit: 
(7) Upholstery Shop, 43-44

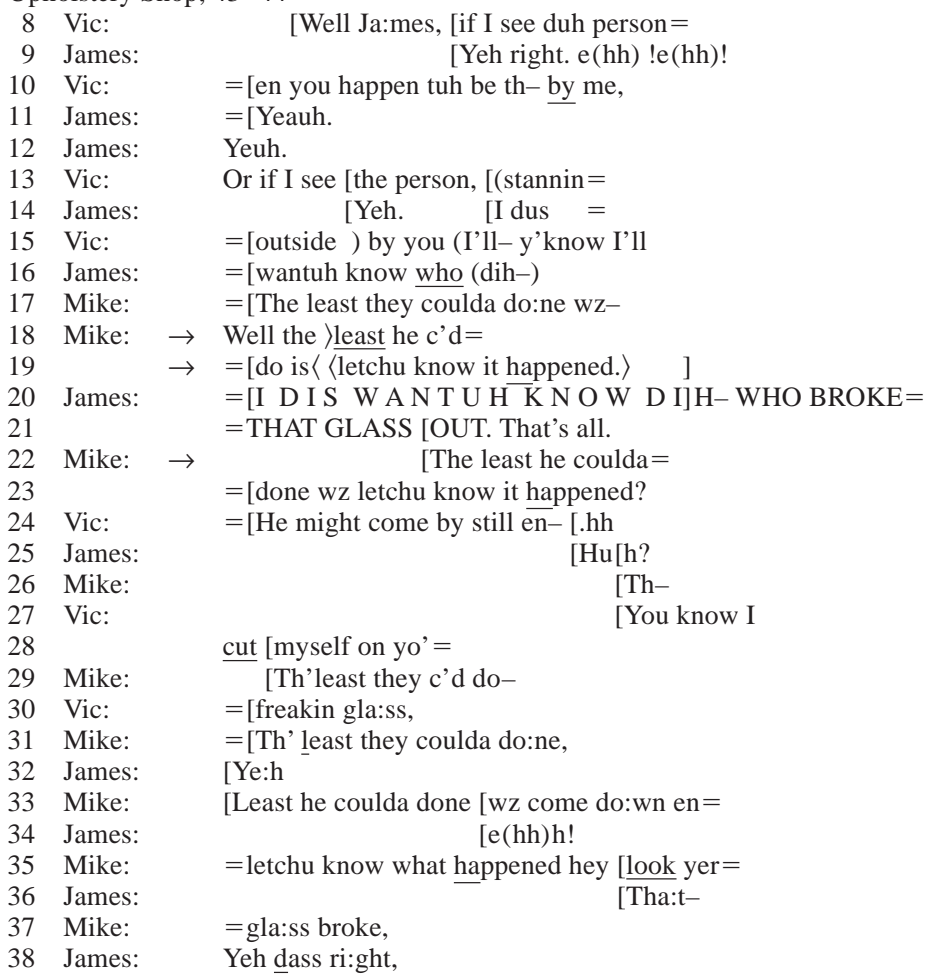

At 7:16-17, Mike's effort to articulate the minimum level of acceptable behavior in this situation is in overlap with James's insistence on knowing who broke the window. Both withdraw from the overlap at the same time, and Mike (at 7:18) immediately restarts his utterance to get it said in the clear. However, Mike apparently registers James's preparation to do the same (a preparation that comes to fruition at 7:20), and he seeks to head off this incipient renewal of the overlap.

We see in Mike's turn, in sharp relief, the way that practices of perturbation as embodied in the pacing of the talk differ when they are deployed at different phases of the overlap. In the pre-onset phase, Mike speeds up (or compresses) the pace of his talk (represented in the transcript by the pair of inward-pointing angle brackets $>X X X\langle$ before least at 7:18, and after is at 7:19), as if to leave no room in which a new speaker could begin. ${ }^{18}$ Once James launches the overlapping talk (at 7:20-21), Mike reacts by markedly slowing the pace of his talk (represented in the transcript by the pair of outward-pointing angle brackets $\langle X X X\rangle$ before letchu and after happened at 7:19), in what we can call the POST-ONSET PHASE of the overlap. The same prosodic dimension or "variable," i.e. pace, is thus subject to different perturbations depending on the phase of overlap trajectory at which it is deployed. 
As its name specifies, the post-onset phase is composed of the several beats, syllables, or words that follow the onset of overlap itself. Here one regularly finds hitches and perturbations which register the response by one or both parties to the fact that another is also speaking. As noted in ex. 7, this can take the form of a marked slowing or retardation of the pace of the talk. Looking again at ex. 6, we see another form of post-onset perturbation, a sharp increase in volume.

(6) Upholstery Shop, 43

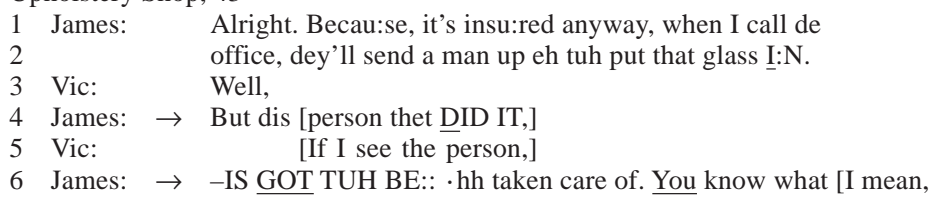

James's pre-onset increase in volume having failed to prevent Vic's entry, James's talk becomes competitive with the sharp increase in volume on DID IT (6:4). Other hitches and perturbations are also found in the post-onset phase - such as sound stretches, cut-offs, and recycles of the beginning of the TCU - but we will forgo here an account of the differential deployment of these practices.

We have already had occasion to take note of the PRE-RESOLUTION PHASE, and the deployment in it of the pre-resolution stretch. We need also to register a POST-RESOLUTION PHASE, which is commonly the locus of hitches and perturbations in turns that emerge from overlap into the clear. For example, at 6:6, just after James' turn emerges into the clear from overlap with Vic's (at 6:4-5), there is a sound stretch (on $B E::$ ) and a break in the progressivity of the turn while an in-breath is taken.

It is not entirely clear what distinct issues are addressed in this phase, but at least one appears to be common and is exemplified here. As noted earlier, the presence of overlapping or competitive talk can warrant practices of talking that are otherwise problematic. Thus speakers in overlap can abort production of a TCU before possible completion (as a way of resolving the overlap), in the face of an otherwise oriented-to and overwhelmingly observed commitment to bringing TCUs to closure once they have been launched. So also, very loud talk, which is understandable as "competitive" while a speaker is talking at the same time as another, is vulnerable to other hearings (for example, as angry, drunk, coarse etc.) while one is talking as sole speaker. Speakers who have deployed perturbations of increased volume in response to simultaneous talk by another may find themselves accountable in quite a different fashion once the overlap has been resolved by the withdrawal or utterance completion of the other speaker; then their loud production may be hearable as angry, etc. The post-resolution phase is the locus for such adjustments, and the hitches and perturbations found there may represent such adjustments from competitive to "solo" production.

This seems to be the case in ex. 6, where James has reacted to Vic's entry by getting sharply louder in post-onset position. This is effective, at least in the short term, since Vic does not immediately continue his utterance. When James con- 
tinues at the same volume, however, he is now hearable in quite a different way; now, he is talking at that volume without a simultaneous speaker as an account incarnate for his speaking that way. It is at the post-resolution hitch that he lowers his volume again to its level before the post-onset deflection. So also in the earlier ex. 5, repeated below.

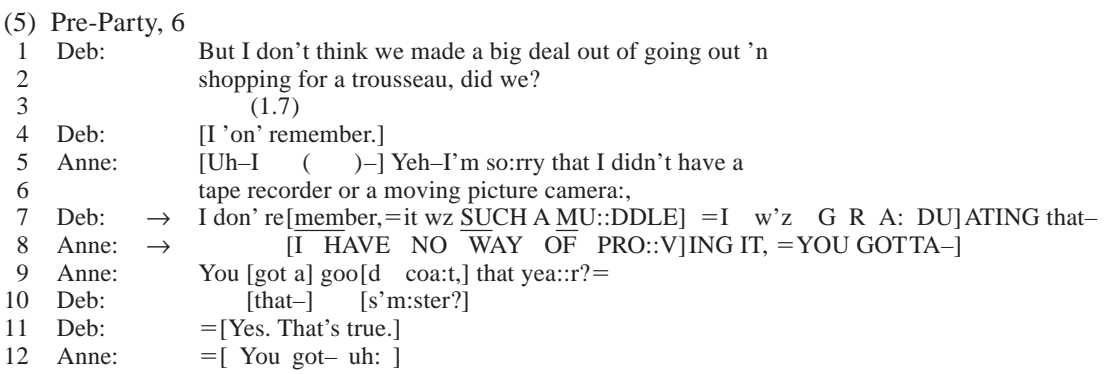

At lines 7-8, after Anne enters the talk in competitive mode at high volume, Deb responds by herself raising her volume, and indeed "upping the ante," as displayed in the transcript's adding underlinings to the capital letters in $\underline{S U C H}$ and $\underline{M U}:: D D L E$. Deb again raises volume at GRA:DUATING; and in the course of that upgrade, Anne apparently withdraws from the overlap, leaving the remainder of Deb's GRA:DUATING being said at high volume, with no competing talk as its account. Just after Anne's withdrawal, after Deb's talk has emerged into the clear in the post-resolution phase, there is a hitch in Deb's talk, after which the volume of the rest of her utterance is reduced. (It may be noted that Anne exploits that hitch in the post-resolution phase to restart her abandoned competing turn; in fact she brings it to completion, leaving it as the point of reference for succeeding talk. $)^{19}$

There may be other phases as well, but these will not be treated here. Worthy of mention, however, is what can be called a POST-POST-ONSET PHASE. Overlaps that grow to substantial length grow IN THE MIDDLE; i.e., what expands is the amount of overlapping talk between the onset and its immediate aftermath, and before the resolution and its immediate anticipation. This can become the arena for exchanges of move and countermove as the simultaneous speakers contest for the turn's space. I will examine an exemplar of such a struggle later, but I omit any more general claims about this phase of the management of overlapping talk. ${ }^{20}$

The preceding sections have depicted various deflections of the production of talk in overlap as resources possibly deployed in the parties' respective practices of management of the onset and trajectory of the overlap, its resolution, and its outcome; and they have characterized a number of phases in the developmental trajectory of an overlap, out of which its trajectory is composed - onset and resolution, with their anticipations and aftermaths. These phases provide the proximate contexts for the deployment of the previously described resources, and they 
may condition the forms those deflections take. It turns out, however, that these phases do not constitute THE MOST PROXIMATE CONTEXTS for the deployment of the deflections. To describe these, we must move to yet another level of detail; we must ask how the resolution of simultaneous talk is actually managed by the speakers, step by step, in real time.

\section{The interactive logic of deployment}

Throughout conversation, "adjacency" or "nextness" (Schegloff 1968:1084) plays a central role in sequential organization. "Next turns," for example, are a strategic position in which parties to talk-in-interaction may "react" to what another has said/done. The default understanding of any turn at talk is that, unless otherwise provided for, it is addressed to what just preceded - to its adjacent prior, or that after which it is "next."

With overlapping talk, however, it is precisely the claim to the turn space that is at issue, and "current turn / next turn" cannot supply the ground on which reactivity or interactivity can be displayed. The relevant level of granularity appears to be the "beat." What exactly constitutes a "beat" is not yet well understood. ${ }^{21}$ For present purposes, I will treat it as substantially equivalent to a "syllable"; but this is essentially a convenient stipulation, to be replaced when careful empirical analysis specifies more robust units to which simultaneous speakers can be shown to be oriented.

Still, there is some evidence that parties to talk-in-interaction can orient to syllable-like beats in monitoring and producing talk. ${ }^{22}$ In exx. 8-10, next turns or continuers are produced in full or partial overlap with ongoing or just-ending turns; we can observe a fine-tuned fit between the several beats of the new speaker's contribution and the beat structure of the talk already in progress.

(8) TG, 05:02-05

1 Bee: $\quad$ nYeeah, $\cdot \underline{h}$ This feller I have- $(\mathrm{nn}) /(\mathrm{iv}-)$ "felluh"; this

2 ma:n. (0.2) t! ·hh He ha::(s)- uff-eh-who-who I have fer

$3 \rightarrow$ Linguistics [is ] real]ly too much, $\cdot \mathrm{hh}[\mathrm{h}=$ ]

4 Ava: $\rightarrow \quad$ [Mm] hm?]

(9) TG, 03:02-04

1 Bee: [Well my aunt went with her anyway this time,

2 Ava: $\rightarrow[\mathrm{Mm}] \mathrm{hm}, \overline{]}$

3 Bee: $\rightarrow$ [My ] mo]ther didn't go.

(10) TG, 11:19-23

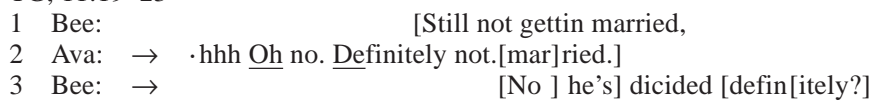

In ex. 8, this fit is embodied in the way the $\mathrm{mm} \mathrm{hm}$ is overlaid onto the continuing talk (actually, this is less a continuer than it is a recognition token for the person reference that has just been achieved, in the face of some trouble, at 8:1-3). In ex. 9 , it is displayed in the way the continuation of the multi-unit utterance-inprogress and the beats of the $\mathrm{mm} \mathrm{hm}$ (here a full-fledged continuer) coincide. In 
ex. 10, Bee starts at 10:3 in a fashion well articulated to the apparent ending of Ava's prior turn - which is grammatically complete in context, and is prosodically delivered with final intonation. The way Bee's talk is designed to continue the pace and beat structure of the prior turn is revealed when Ava then adds an increment (married) to her otherwise completed turn; its two syllables coincide precisely with the first two beats of Bee's new turn. Thus the choice of the syllable/ beat as a unit of organization is not without some grounding in the observable features of the talk and speakers' orientation in their production, and these are displayed in episodes of overlap which are NON-competitive, such as exx. 8-10.

The topography of sequential and interactive organization in overlapping talk, then, may be supplied by the successive beats that compose it (which will not, of course, always be so precisely coordinated and aligned as in the three exemplars just examined). What the simultaneous speakers do in each increment of the overlapping talk may then be inspected - in the first instance by the interlocutors (or "co-locutors"), and accordingly by researchers - FOR THE SORT OF REACTION OR STANCE THAT IT EMBODIES RELATIVE TO THE JUSTPRECEDING CONTRIBUTION BY THE OTHER, i.e., what the other did in the justpreceding beat. The underlying orientation and practice being entertained here may be explicated along the following lines, invoking "prototype speakers" Les and Pat; for convenience, we will consider the case of simultaneous starts, in order to set aside (at least in the most obvious ways) issues of prior claims to the turn space.

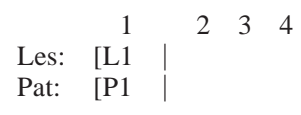

As Les and Pat begin talking simultaneously, each produces a first beat of his talk, rendered here as L1 and P1 respectively. The next beat is the place at which they (unavoidably) register and enact a reaction to what has occurred at beat 1 .

As Les produces L1, he can hear Pat producing P1. This is the first indication (we will assume no pre-onset activity here) of simultaneous talk, and of the management issue it poses for the achievement of "one-at-a-time." A first set of alternative possibilities for Les is to stop talking at this point, not producing a second beat; or to continue talking, producing a second beat. Pat gets the same "input," and so faces the same issue and the same alternatives. If either Les or Pat elects not to produce a next beat, the overlap is resolved (at least for the moment); if both do so, the overlap is resolved, but is replaced by silence - an alternative turn-taking problem that requires resolution. ${ }^{23}$

If both Les and Pat elect to continue, they produce next beats of their respective turns L2 and P2.

\begin{tabular}{lr|r|rr} 
& 1 & 2 & 3 & 4 \\
Les: & {$[$ L1 } & L2 & & \\
Pat: & {$[\mathrm{P} 1$} & P2 & &
\end{tabular}


Each now hears what stance the other has taken up in regard to the fact that they are talking simultaneously; and each must now elect a further course of action in response both to the fact of simultaneous talk and to the stance the other has taken to it.

Actually, in producing L2 and P2, Les and Pat have other resources and practices as alternative ways of proceeding which must be incorporated into the account. Each can produce the second beat in "solo production," i.e. in the mode of turn production employed when talking as sole speaker (assuming that their first beat was articulated in solo production); or each can shift to "competitive production" by deploying any of the hitches and perturbations described earlier, in what should be recognizable as the post-onset phase of the overlap. That is, aside from continuing into a second beat, each party can do so in a fashion designed to project "continuing to continue." Let us amend our previous display to reflect a move by Les to "upgrade" to competitive production, underlining L2 to display production at increased volume:

$$
\begin{array}{lr|r|rr} 
& 1 & 2 & 3 & 4 \\
\text { Les: } & {[\mathrm{L} 1} & \mathrm{L} 2 & & \\
\text { Pat: } & {[\mathrm{P} 1} & \mathrm{P} 2 & &
\end{array}
$$

At the second beat, then, Pat hears not only that Les has not dropped out of the overlap, but also that Les has exhibited an upgraded claim to this turn space. It is at beat 3 that Pat will need to react to this move by Les. Again, there are several "strategies," or "tacks," available. In the face of Les's continuation and upgrade to competitive production, Pat can now withdraw, withholding further talk or even self-interrupting the remainder of P2-in-progress. Or Pat can stand firm, producing a third beat (and a fourth, fifth etc.) in continuing solo production. Or Pat can "rise to the occasion," responding to Les's move to competitive production by moving to competitive production in turn. If Pat takes this second or third tack, and Les continues on the course taken at beat 2 , we have serious competition for this turn space, in that neither party has displayed willingness to defer to the stance taken up by the other:

$$
\begin{array}{lr|r|r|r} 
& 1 & 2 & 3 & 4 \\
\text { Les: } & {[\mathrm{L} 1} & \underline{\mathrm{L} 2} & \underline{\mathrm{L} 3} & \\
\text { Pat: } & {[\mathrm{P} 1} & \underline{\mathrm{P}} 2 & \underline{\mathrm{P} 3} &
\end{array}
$$

At beat 4, Les may now drop out in the face of Pat's having risen to the occasion in the face of Les's strongly projected claim to the turn; or Les may continue at the same "level," or may raise the ante by deploying further resources of competitive production - getting louder still, or higher in pitch, or recycling the turn-so-far. Pat too may take any of these tacks. Should the overlap involve both of them taking the last of these courses, we may have the sort of extended "floor fight" that expands the phases of the overlap to include a "post-postonset" phase. We will examine such an extended overlap competition below, but such extended floor fights are relatively rare. Enough has been said to sug- 
gest the interactive texture of the early phases of an overlap, and we should take stock of the characteristic outcomes of the actual tacks adopted by simultaneous speakers.

\section{RE S OLU T I O N S}

A great many overlaps get resolved via a very few developmental trajectories, which are briefly characterized and exemplified below.

\section{Overlaps resolved after one beat}

Many overlaps are resolved after a single beat by the withdrawal of one or both parties at the first evidence that simultaneous talk is in progress. Exx. 11-14 are cases in point:

(11) TG, 06:08-12

1 Bee: hh Yihknow buh when we walk outta the cla:ss. $=$

2 Ava: =nobuddy knows wh't [wen' on,]

3 Bee: $\rightarrow \quad[$ Wid $-\cdot$ hh $] \mathrm{h}=$

4 Bee: $\quad=$ Li $($ hh $)$ ke wu- $\cdot$ hh Didju $n$ - Didju know what he wz talking

5 about didju know wh't [structural paralysis was=

6 Ava: [dahhhhh

(12) FD, IV:141

$$
\begin{array}{lll}
1 & & ((\text { pause })) \\
2 & \text { B: } \rightarrow & \text { [Please- } \\
3 & \text { A: } & \text { [Wha' was that again ma'am? }
\end{array}
$$

(13) US, 2

$$
\begin{aligned}
& 1 \text { Mike: =y'couldn't git[ta hol-] } \\
& 2 \text { Vic: } \rightarrow \quad[\mathrm{m} \text { a n ] tell 'im. }
\end{aligned}
$$

(14) HG, 1

$$
\begin{aligned}
& 1 \text { Hyla: } \rightarrow \text { [Bu:t] } \\
& 2 \text { Nancy: }[\mathrm{M} \mathrm{y}] \text { face hurts. }
\end{aligned}
$$

In each of these exchanges, one of the parties drops out of the overlap after no more than a single beat in one of the turns. (The single beat is not always in the turn of the one who drops out; in ex. 13, two beats of Mike's talk are implicated in overlap with one beat of Vic's, before Mike drops out.)

\section{Longer overlaps resolved after competition}

Of overlaps that survive the first beat, a great many are stopped within one beat after one of the speakers upgrades the talk to competitive production. They are stopped by a cut-off by the recipient of the upgrade. Exx. 15-19 are cases in point; in 15-17, one party drops out upon the other's completing the upgraded beat; in 18-19, the drop-out occurs one beat AFTER the other's upgrade: 
(15) US, 1

1 Vic: $\quad$ Be[cuz]I'm] deh en I'm gon'...

2 Mike: $\rightarrow$ [Did] $\overline{\mathrm{ju}-]}$

(16) FD, IV:141

$1 \mathrm{~A}: \rightarrow$ I [say] c'd-]

2 D: [Her] name] is Kellerman, si:r.

(17) TG, 01:43-44

1 Ava: $\quad\left[{ }^{\circ} \mathrm{B}\right.$ 't asi]de fr'm that it's a'right.

2 Bee: $\rightarrow$ [So what-]

(18) US, 45

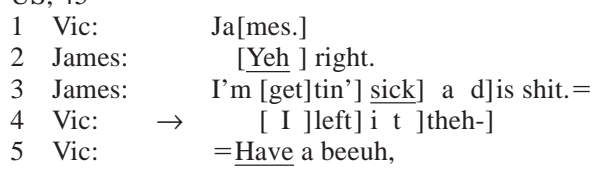

(19) US,2:39-3:02

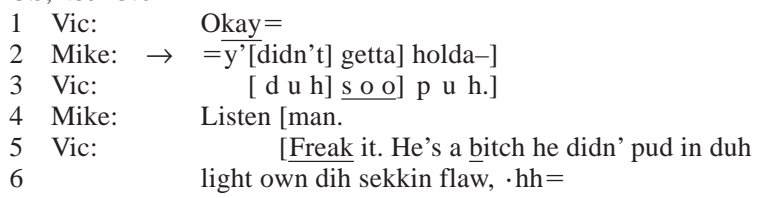

In ex. 15, Vic goes into competitive production at the second beat of the overlap (as in the third of the Les/Pat diagrams in the preceding section), and Mike withdraws before producing a third. Ex. 16, taken from a call to a fire department, is straightforward in A's cut-off in the face of D's move to competitive production with name, as is Bee's withdrawal in ex. 17 in the face of the upgrade of aside. In ex. 18, Vic cuts off the beat following James's markedly louder sick; and though he reenters a moment later, it is not with what he had been saying in the aborted turn, but with a suggestion possibly addressed to the tenor of James's talk. In ex. 19, Mike is producing two syllables to every one of Vic's (at lines 2-3). When Vic gets sharply louder at the second beat, Mike cuts off at the end of the third, although he immediately tries to reclaim the turn (at 19:4) with a summons deployed as an interruption marker - an effort that fails as Vic comes in on it already in competitive mode. The salient observation here, however, is Mike's withdrawal in the beat following the upgrade, even though he immediately reverses course. Note as well that, in exx. 15-17, there is no further talk by the recipient of the competitive upgrade after the beat in which it is deployed, whereas in exx. 18-19 the recipient of the upgrade is less immediately responsive to it and persists for one additional beat. ${ }^{24}$

As a separate observation, it is worth noting that there is often a move to competitive production in the second beat of the overlap, as in exx. 15-17 and 19 above - or, if not there, in the third, as in ex. 18.

If we take together two kinds of overlap - those that are resolved when one party drops out as soon as the overlap is revealed (after one beat), and those that are resolved when one party drops out as soon as the other takes up a competitive 
stance (often in the second beat, with drop-out by the third) - then we find that the vast majority of overlaps are resolved to a single speaker by the third beat. This was one of the aggregate observations with which we began (see above, "Constraints on an overlap resolution device"): The vast majority of overlaps are over very quickly. "Very quickly" has now been given a somewhat more precise formulation; and the aggregate outcome has been grounded in practices which the parties bring to bear, beat by beat, in singular local instances of overlap.

A great many overlaps may be engendered by relatively straightforward turntaking "miscues," with little interactional investment by the parties. For example, an incipient next speaker may project incorrectly where a current speaker means to end a current turn, and may consequently start in overlap. Or two current non-speakers may each self-select to take next turn, and thus start simultaneously. Overlaps that are resolved quickly may often reflect a lack of investment by either party in securing the turn space at issue.

However, either party or both parties may have outside-turn-taking interests in persisting in the overlap, rather than in withdrawing; and if both persist, long and multiply upgraded overlaps may result. Indeed, extension of an overlap past the initial 3-4 beats that represent "quick resolution" can itself allude to, or invoke the possibility of, such other interests or issues. Such "interests" may include needing the current turn position in particular, in order to do a particular responsive action which requires next-turn position; or the recent course of the interaction, with its history of turn allocation and contestation; or status issues for which any sort of deferral is consequential (though this in itself does not determine whether insisting on persisting or "noblesse obliging" will be the status-marking course of action). ${ }^{25}$ But these are simply a few of the vernacularly familiar grounds which parties may understand to be driving contestation of an overlap. Persistence in the beat-by-beat development of the simultaneous talk is one way a speaker has of displaying that SOME interest(s) is/are being pursued, and that identification of the interest(s) may be possible for the co-participants in that local setting, in that moment. Such identification may be construed by co-participant(s) in ways uncertainly related to what is informing the speaker's conduct. In any case, what is driving the extension of the overlap (or what the parties may construe to be driving the extension of the overlap) will be furnished by the particulars of the context: whatever the parties take to be features of that interactional moment that may prompt persistence, and that persistence may invoke as relevant. Academic analysts may gloss classes of such features (status, power, gender, emotional reaction etc.), but the parties attend to the particulars informing that specific episode - which may, of course, include "general" features.

Here we examine briefly one episode of extended competitive overlap, both to exemplify the applicability of the analytic resources we have developed and to explore the sorts of dense interactional scenarios that can get played out in the arena of overlap. 


\section{AN INTERACTIONALLY DELICATE EXTENDED OVERLAP}

In ex. 20, three generations of a family are in the car on the way to an extendedfamily party. Dick and Anne are the oldest generation (in their late 50s or early 60s), and Deb is their daughter. Deb's husband and young child are also in the car, as is her 20-year-old brother, but they do not participate in this exchange (although the grandchild is made the ostensible addressee of an utterance at 20:33 and 20:36). By a circuitous route, Anne has come to voice the claim (20:1-2) that, when she was a young woman, she used to buy six pairs of shoes every six months. (In Appendix 2 the reader can see the segment from lines 19-41 presented in a horizontal format, like a musical score.)

(20) Pre-Party, 2-3

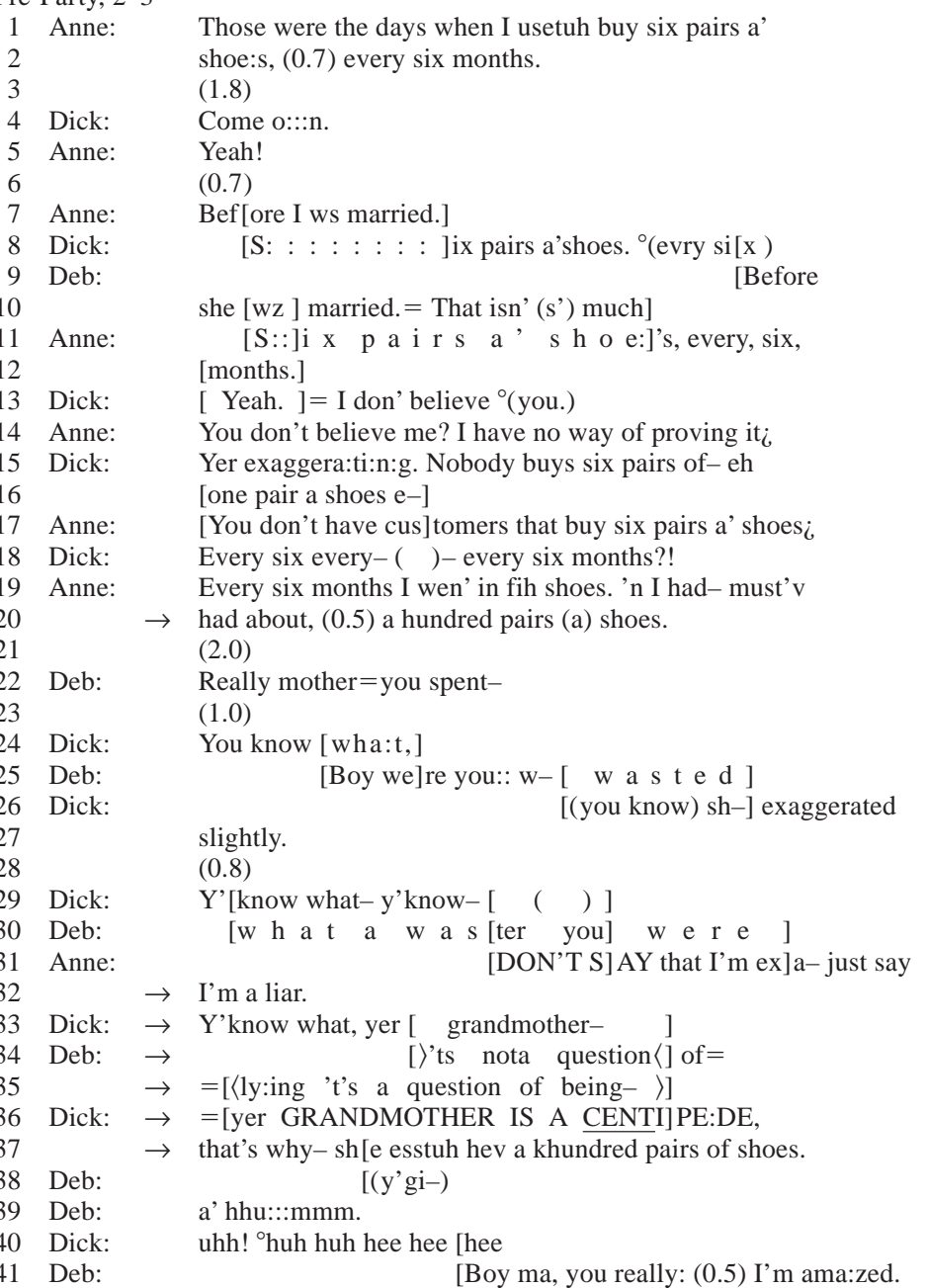




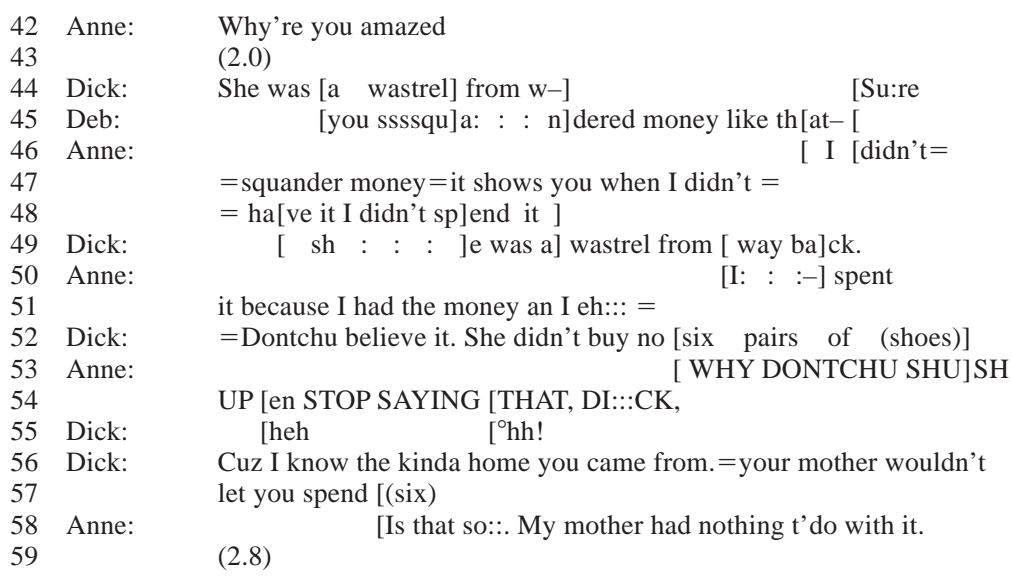

Anne claims to have bought six pairs of shoes every six months when she was a young woman, in the face of the skepticism (and disapproval) of her daughter, and the outright challenge of her husband (himself a salesman of women's shoes). When she crowns her claim with the estimate that she must have had a hundred pairs a shoes (20:19-20), her husband characterizes this as a slight exaggeration (20:26-27), a description which Anne takes as a euphemism for being called $a$ liar in an utterance (20:31-32) in which she takes up a stance of being offended. Following this utterance is the protracted overlap between Dick and Deb (father and daughter) on which we will focus (20:33-39).

At 20:33, Dick begins the turn with which he will in effect respond to Anne's complaint, an utterance carried through at 20:36-37. At the same time, Deb responds to her mother's taking offense, at 20:34-35.

Dick's tack is apparently to defuse the situation with a joke (he is the punster complained of earlier in ex. 4 for being this version of jovial). Actually (or as well), however, he is trying again to make a pun he has been attempting since Anne's earlier reference to a hundred pairs of shoes (20:20). Note that, at 20:24, he begins You know what before withdrawing in favor of Deb's overlapping talk. Again at 20:29 he begins with you know what, this time withdrawing in the face of competing talk by both Deb and Anne - the latter being the very turn in which she complains of being called a liar. Now, at 20:33, Dick tries yet again; his starting with the same words you know what constitutes a practice for claiming "what I am saying/doing now is what I was trying to say/do when I used these words before" (Schegloff 1996b:199-202). This time he pretends to address himself to his granddaughter and proposes your grandmother is a centipede [a creature with one hundred feet], that's why she needs a hundred pairs of shoes. Although temporally occurring in the aftermath of Anne's complaint, there is a "trail" here which shows that the origins of Dick's turn at 20:33-36-37 go back rather farther. Still, it is here that he tries (again) to say it. 
Deb's talk does appear to be directed specifically to her mother's complaint about being called a liar. Her tack is to deny her mother's charge of having been called a liar, and thereby to neutralize the associated offense. It is in their simultaneous efforts to get their respective turns said in this turn position that Dick and Deb sustain an extended, multiply upgraded overlap.

Although Dick's joke might well serve to detoxify the atmosphere poisoned by Anne's taking offense, from his start at 20:33 (Y'know what), Deb can glean only that he is starting again what he was starting earlier, before (most importantly) his reference to Anne's "exaggerating" and her negative reaction to it. Deb therefore has no grounds for analyzing Dick's incipient turn as directed to Anne's offendedness. She then launches an utterance of her own, designed to display that it IS addressed to Anne's expressed concern. She launches her turn with compressed pace (within the $>X X X<$ marks in the transcript at 20:34), a mode of production designed to circumvent or overcome competition - and one which, by its preonset phase realization, only glancingly treats Dick's turn as in competition with hers, ${ }^{26}$ perhaps relying on their ostensibly different addressees: Dick's is done as an utterance to the granddaughter ( yer grandmother ...), and Deb's to her mother (it's not a question of lying ....).

Dick DOES, however, come to treat this as a competition for the same turn space. He cuts off his turn-so-far in post-onset position (20:33) and recycles it (20:36), this time in heavily upgraded (i.e. competitive) volume. Note as well that, in the meantime, Deb had herself begun moving to competitive production with the overstress on lying at 20:35 (in the sound stretch marked by the colon), an upgrade that is massively countered by Dick's much louder production.

Note then that Deb does NOT withdraw in the face of this major upgrade of competitive production by Dick. Rather, she responds by shifting the pace of her talk from the compressed production with which she began to the stretched-out production characteristic of within-overlap competition (between the $\langle X X X\rangle$ marks in 20:35). That is, rather than capitulating to Dick's move, Deb counters it. Note, finally, that in response to this counter, Dick upgrades his volume yet further, virtually shouting the first syllable of CENTIPEDE at the top of his lungs, and this in the confined quarters of the car. To this final counter-upgrade, Deb capitulates, with the cut-off on being at the end of 20:35. (Note, by the way, the post-resolution hitch at that's why in Dick's continuation in 20:37, as he gears down from overloud competitive production to solo production.)

We can see here the deployment of the resources and practices of competitive production (sketched earlier in this discussion), as well as the point and counterpoint of their deployment and reaction to it, and the several rounds of upgrading pressed by the parties before they arrive at resolution of the overlap to a single speaker. This extended overlap exemplifies something other than a turn-taking muddle in which neither party has any special interest. Rather, it invites consideration of what outside-turn-taking interests are involved here that prompt each party to resist being forced out, and to counter the other's persistence. In the first 
instance, it invites such consideration from the parties themselves in the very course of pursuing the overlap to the extent they do. It can, however, mobilize the same interest in us as external, academic analysts.

Here, it seems apparent that the "extraneous" interests do not concern status differential. Considerations of age, gender, and kinship hierarchy, as elsewhere manifested in the interactional conduct of this family, all converge here to favor Dick over Deb - whether to favor his emerging with the turn, or to favor his humoring of his junior competitor by withdrawing. Neither of these outcomes seems to be oriented to by the parties. So what Is driving this extended overlap?

I have already alluded both to the situational and sequential contingency, and to its local contributors in this case. Both parties to this overlap seem committed to getting what they are saying said IN THIS TURN POSITION, and not later; and there are good grounds for each one's orientation.

Dick, as already noted, is trying to make a pun. This is a form of "wisecrack," or repartee, that depends strongly on quick response, almost always in next turn, since it plays off something said by another rather than being entirely selfcontained. It is at best awkward, and at worst useless and embarrassing, to try to retrieve earlier talk for the purpose of making a wisecrack about that talk or off it. It is virtually a confession of failure to have been quick enough: By displaying the need to retrieve, one is in effect underscoring that one failed to deliver on time.

Dick's centipede line was, on this account, due shortly after 20:20. It has already been much delayed, then, by the time of the turn position in which this overlap occurs - first by two full seconds of silence at 20:21, and then by another second after Deb's abandoned expression of surprise at 20:22. Then, as noted earlier, Dick's effort to make the wisecrack at 20:24 encounters Deb's moral indictment of her mother, and Dick's effort to mitigate the charge by calling Anne's claim an exaggeration. His next effort, in 20:29, encounters insistence by Deb on her moral indictment. For the interactional move that Dick is trying to bring off, time is running out. Indeed, it may already have run out, hence his heavy-handed underscoring of the connection of centipede to the earlier - now MUCH earlier and almost remote - hundred pairs a shoes. His commitment to bringing this pun/wisecrack to fruition is probably what mandates its implementation IN THIS VERY TURN POSITION NOW, with no suffering of further deferrals. ${ }^{27}$

Deb, on the other hand, seems committed to addressing an immediate, delicate interactional problem. Her mother Anne proposes to take herself to have been called a liar. This can be traced, however, not to Deb but to Dick, who was the author of the offending exaggerating. On the other hand, Dick's comment was offered in mitigation of an equally serious moral charge of wastefulness leveled by Deb; so if there has been offense, Deb may well take herself to be as fully implicated as Dick. In any case, she now seeks to have the offensiveness mitigated, and this ought to be done at the first possible opportunity. If retraction is to be done as a credible response, it needs to be done next, and that mandates THIS turn space - the one following the expression of offense-taking. 
If Dick needs this turn position for his wisecrack, then Deb needs it to mollify her mother. In any case, both need it, or conduct themselves as if they do. The outcome is a protracted overlap in which each seeks to get done that which needs to be done NOw. The extensiveness of the overlap competition can lead to inquiry into the interactional projects that fuel it. ${ }^{28}$

OTHER ORIENTATIONS TO OVERLAP MANAGEMENT:

ALTERNATIVE FORMS OF "SUCCESS"

The discussion so far may have suggested that the only concern to which parties are oriented in managing overlap is that of "survival" in the competition for the turn space. The occurrence of overlap is problematic for an organization of talkin-interaction designed for, and predicated on, one speaker talking at a time. Overlapping talk represents a departure from the turn-taking premises of this organization of interaction, and various elements of the organization of interaction press for its resolution. The integrity of the organization of interaction, and of any of its occasions, is indifferent to how the overlap is resolved - to who ends up with the turn. As we have seen, however, participants may on occasion display a clear interest in the outcome and may actively and persistently seek to be the "survivor."

Because we have been tracking the organizational device - the set of practices - by which this issue is worked out, we have focused largely on competition and its goal of survivorship. This is conventionally the most dramatic and engaging scenario of turn-taking: the "fight for the floor." It is important, however, to recall the larger picture in which these instances of contestation and competition figure - and to remember that their incidence is far less than their dramatic interest. Recall, then, that we began by exempting four classes of overlapping talk from this inquiry because the circumstances of their production, and/or the stances of their protagonists, rendered them unproblematic sequentially and interactionally. These involve, to a substantial degree, one or another version of collaboratively oriented simultaneous talk. We then noted that, of those overlaps that DID appear (potentially) problematic, a great many end after one beat, i.e. at the first sign that overlap is in progress. Together, these collections of occurrences represent a hefty share of all overlaps - a share further expanded by those overlaps that resolve at the first sign of insistence by one of the participants. Extended competitive overlaps of the sort just examined are, then, by no means common. Interest in them is engendered more by their drama and by the symbolic weight which may be attached to them than by their relative recurrence. It is not the case that "who says overlap says fight for the floor."

But we need to set such contested overlaps into proper perspective in another respect, one that deserves more than the cursory attention to which it must be restricted here. It is not only frequency that is at issue, but also the potential relevance of several other orientations that participants can bring to particular 
episodes of overlapping talk - several criteria of "success" as an alternative to survivorship in the contested turn space. Three such alternatives deserve at least passing mention.

\section{Persistence to completion}

Some parties to overlap, on some occasions of overlapping talk, seem oriented not so much to surviving in the turn (with the implied withdrawal by others) as to bringing their own talk to its designed and projected completion. Ex. 21 offers a case in point.

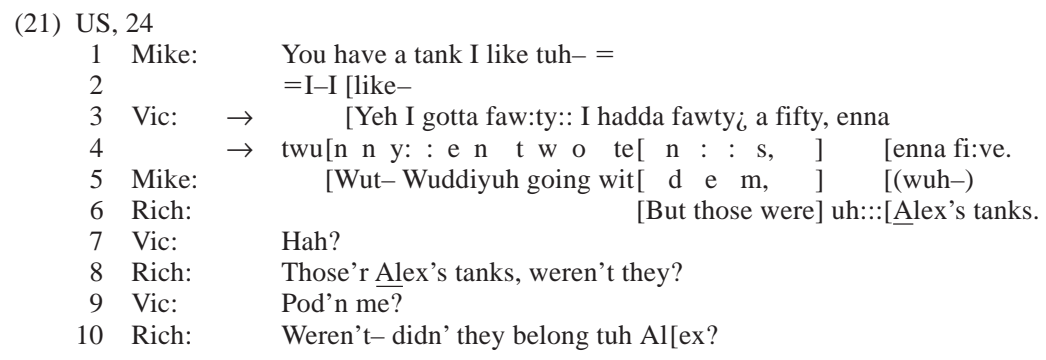

At 21:3-4, Vic seems oriented largely to producing the list of his fish tanks to completion - orienting minimally, if at all, to the talk of Mike and Rich which intersects his. (For other instances, cf. inter alia 2:15-16, 2:19-20, 4:2, or 22:11-13). This is an imperfect exemplar of one kind of conduct in overlap which runs counter to all the description earlier in this article. Some speakers, on some occasions, continue talking in solo production, with no hitches or perturbations, as if no one else were talking at all. ${ }^{29}$ Such speakers embody, even more fully than does Vic in ex. 21, an apparently exclusive orientation to producing their own talk to completion, whatever else may be going on. Paradoxically, this practice of talking in overlap may be the "strongest" of all in the stance which it adopts and conveys to co-participants, despite its failure to deploy any of the resources of competitiveness, precisely in its stance of non-recognition of simultaneous talk in the first instance.

\section{Persistence to projecting the thrust of the turn}

Some parties to overlap, on some occasions of overlapping talk, seem oriented not so much to surviving in the turn or to getting the whole of their turn-constructional unit articulated, as they are to bringing their turn to the point at which its thrust or upshot has been projected or is recognizable. ${ }^{30}$ Deb's withdrawal from the overlap examined in ex. 20, while not a transparent exemplar of this orientation, suggests an orientation to replacing a preoccupation with "lying" with some other concern; this outweighs both the particular other that will replace it, and the need to speak her piece to completion. 


\section{Achievement of sequential implicativeness}

Most important of these orientations, alternative to survival in the turn position, is an orientation by a party to having his/her part of the overlap be SEQUENTIALLY CONSEQUENTIAL, IF NOT SEQUENTIALLY IMPLICATIVE (Schegloff \& Sacks 1973:296 n.) That is, between one party's talk and the talk of the simultaneous speaker, it should be the former's talk to which subsequent talk is addressed, rather than the talk of the latter. What makes this alternative orientation especially important, in understanding conduct in overlap, is that it may lead speakers to manage their part in an overlap quite differently than they would if they were committed to survivorship alone.

Consider, for example, ex. 22. Kathy and Dave are hosting longtime friends Rubin and Frieda for dinner. The guests, and Rubin in particular, have complimented Kathy on something which she has handwoven, and she is explaining what she meant by saying that it wove itselfonce it was set up. Lines 1-2 complete her account.

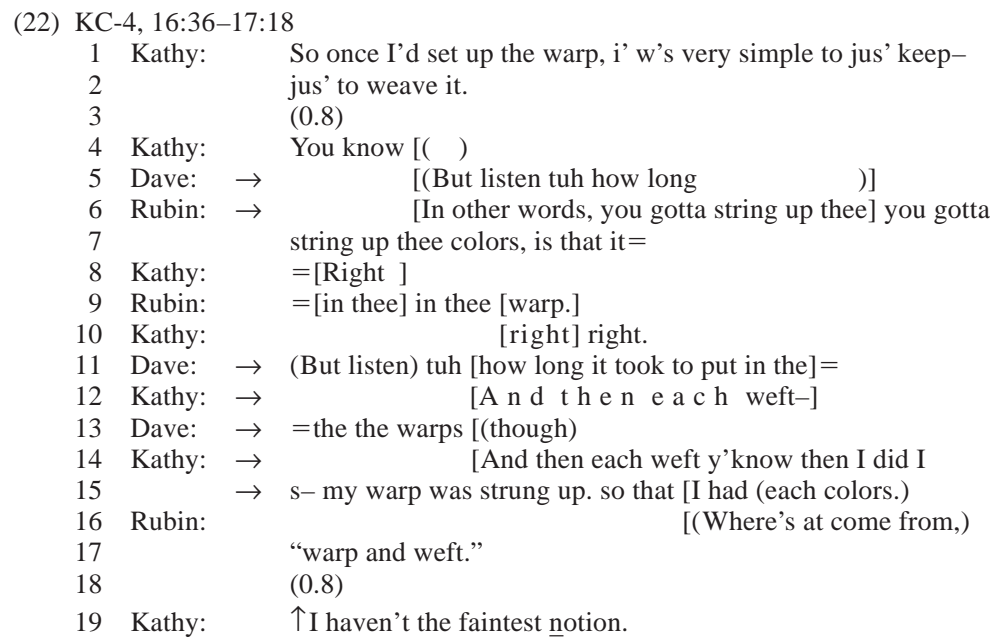

At 22:5-6, Kathy's husband Dave and Rubin start simultaneously: Rubin to pursue and check his understanding of Kathy's account, and Dave to suggest how much work was involved, despite Kathy's modest disclaimers. Dave withdraws in favor of Rubin's clarification; and once Kathy has multiply confirmed Rubin's understanding (22:8 and 10), Dave tries once again (notice his re-use of the same words) to introduce the scope of the task (22:11-13). This time it is Kathy whose talk is in overlap with his, and this time SHE withdraws in favor of his utterance (22:12). Or so it appears.

But note that, as soon as Dave comes to the projected possible completion of his turn, Kathy starts up again (at line 14). She uses the same words as she had before $(22: 12)$ to show that what she is saying now is what she was trying to say 
before (Schegloff 1996b); but having established that point, she drops that wording and re-formats the talk in her turn. Thus Kathy has in effect lost the battle in order to win the war. Her withdrawal (22:12) cedes the turn space to Dave; but her restart of her turn, on the completion of Dave's, subverts any possibility of Dave's turn shaping the immediately following course of the talk. In fact, it is Kathy's talk to which the next turn is addressed, ${ }^{31}$ not Dave's. Dave's utterance is never addressed in the subsequent course of the interaction. ${ }^{32}$

Aside from the fact that this differing orientation to the management of overlap mandates different conduct for a party to the overlap in its course, there is an important systemic consequence as well. A practice such as that implemented by Kathy in ex. 22 allows contests over turns to be disengaged from contests over sequences, over the longer-term trajectory of the interaction. Were this tack not available, losing the competition for a turn space might entail loss of the capacity to shape the ensuing talk, and the capacity of that ensuing talk to shape the later course of the interaction. In fact, however, the consequentiality of losing the turn position can be quite restricted, and the turn position can be sacrificed precisely in order to affect longer-term aspects of the conversation.

A further consequence is the equivocality of the withdrawal of a party to overlap from competition for survival. If survival in the turn space were the only success criterion, then dropping out would be decisive - a loss. With the alternative success criterion of sequential implicativeness, withdrawal may be merely an instrument for a different order of success; and this itself then informs the competition for survival in the turn space. ${ }^{33}$

\section{OVERLAP AFTERMATH}

To this point, our examination of the phases at which overlap-oriented deployments of resources might be placed in an overlap's trajectory ended with a phase we termed "post-resolution." One practice whose "natural" home is in this phase is the gearing-down of talk which had been upgraded to competitive production, returning it to solo production. This practice may recommend itself to speakers by virtue of their vulnerability otherwise to being heard as angry, rude, coarse etc.

But the moments immediately following overlap resolution figure in another fashion as well. They are a place in which the aftermath of the overlap, if any, gets worked up and displayed - not the ONLY place, but the most commonly exploited one.

How can an overlap figure in a spate of talk-in-interaction? What stance can the parties take toward its having occurred?

(a) It can be taken notice of, i.e. registered or not.

(b) If registered, it can be taken as problematic or not. The "not" may itself be differentiated into an unnoticed blip on the one hand, or a positively sought collaborative co-construction on the other hand, to cite but two possibilities. 
(c) It may make relevant a response at the level of sheer turn-position occupancy, or not. (In the guise of "competition," this has been the focus of the present essay to this point.)

(d) It may be attended to for its bearing on larger units in the interaction, such as shaping the immediately ensuing direction of talk, or it may not.

(e) It may be attended to for its consequences for other, central elements of the talk, such as its hearability/understandability/graspability. Overlap is taken possibly - but not necessarily - to impair the efficacy of the talk implicated in it; and the parties may attend to whether the talk (i.e. its production) has been impaired or not, and whether its understanding has been impaired or not.

This is at least a substantial part of the range of aspects of overlapping talk that can be oriented to by the parties as somehow figuring in the course of the overlap's development and in its aftermath. It is in its aftermath that we will now briefly examine different forms and degrees of taking notice of, and registering the consequences of, an overlap that has just been resolved - whether one or more participants withdraws prematurely, or when one or more of its component turns comes to a "natural" possible completion. This is a place (including the phase I earlier called "post-post-resolution") at which one or both of the parties can take up a stance toward the "event" that has just occurred.

Alternatively, they may choose not to treat it as an event at all. Some parties on some occasions may continue talking in solo production throughout the course of the overlap, deploying none of the resources we have described and showing no "effects" of that simultaneous talk - displaying no post-resolution hitch or the like. The stance they have in effect taken up is to have taken no notice of another's talking at the same time. ${ }^{34}$ A case in point is furnished by Vic's utterance at lines 27-28 of the lengthy exchange introduced earlier as ex. 2, and repeated here as ex. 23.

(23) US, 43

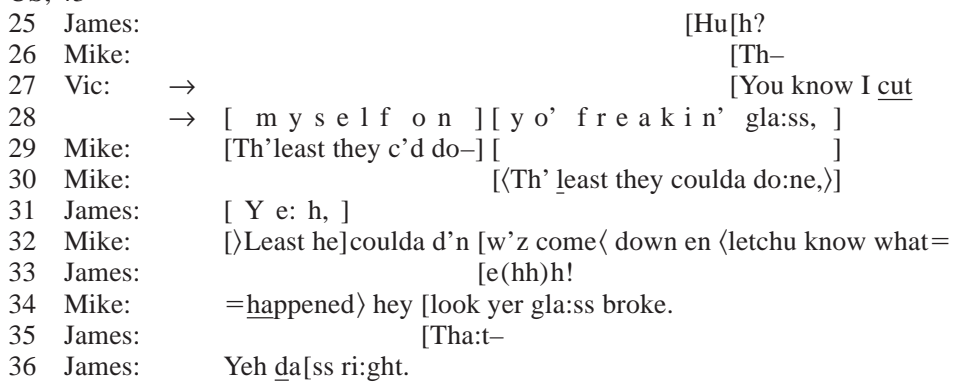

Vic's utterance, You know I cut myself on your freakin' glass begins in overlap with the start of Mike's fourth try to get his utterance out and heard (i.e. $T h$ - as the start of The least they could've done ...); it is, therefore, a potential competitor for the turn-position - in contrast to the Huh? 23:25, which is just ending. Vic's utterance appears to be produced in virtually total disregard of Mike's simulta- 
neous talk, ${ }^{35}$ which he seems not to register (unless the stress on cut is taken as a pre-onset bit of competitive production). Here, then, is one possible stance: displays no notice taken.

One of the subtlest displays of HAVING registered the overlap as an "event" in the talk occurs when no ripples mar the smooth surface of the turn's production while the overlap is in progress, but when, on its resolution, a post-resolution hitch shows that notice had been taken - that the occurrence had been monitored, and that it has now been stopped. Ex. 24 is repeated from the earlier ex. 22:

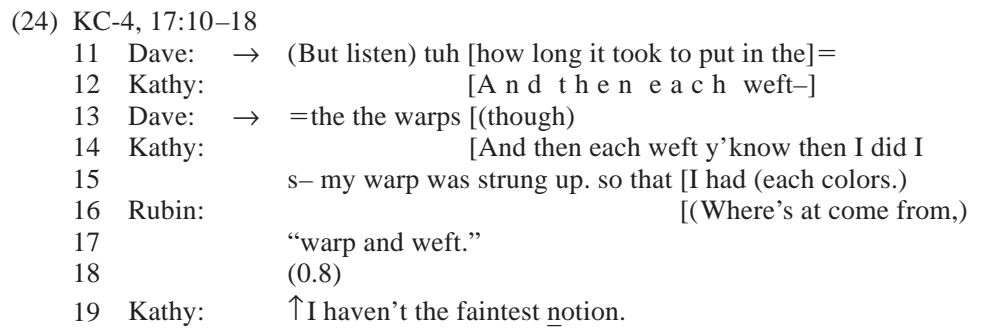

At 24:11, Dave is trying again to articulate a turn which he had earlier abandoned in overlap with Rubin. Here he seems determined to get it said; and he produces it unruffled by the simultaneous talk of Kathy, who is addressing the same recipient, Rubin. Note that there are no signs in Dave's talk of competitive production, or even of registering the "fact" of Kathy's simultaneous talk while it is ongoing. But just after Kathy abandons her turn-in-progress, thereby resolving the overlap, a slight hitch appears in Dave's talk (the multiple repeats of the at 24:11 and 24:13), registering that notice HAD been taken of the simultaneous talk's occurrence and end - a slight blip on the conversation's (and Dave's) radar screen.

More substantial as a form registering overlap as an event is the recycled turn-beginning (Schegloff 1987a). Here the resolution of the overlap occasions a recycling of the turn-so-far of the "surviving" claimant for the turn space. Not only does its placement display close attention to the fact and developmental course of the overlap; the talk that is implemented there shows that the overlap is taken possibly to have impaired the implicated talk, and an effort is made by the speaker of that talk to repair whatever impairment it suffered by redoing it "in the clear," where it is not vulnerable to the same source of trouble. ${ }^{36}$ In ex. 25, Kathy and Rubin are discussing the proper understanding of the diagnosis of a mutual friend's illness:

(25) $\mathrm{KC}-4,7: 13-27$

$\begin{array}{ll}1 & \\ 2 & \text { Rubin: } \\ 4 & \\ 5 & \text { Rubin: } \\ 6 & \end{array}$

(0.5)

Well thee uhm (.)(a paz) they must have grown a culture. (0.5)

You know, (.) they must've I mean how lo- he's been in the hospital for a few day:s, right?

$\{(1.0) / . h h h\}$ 


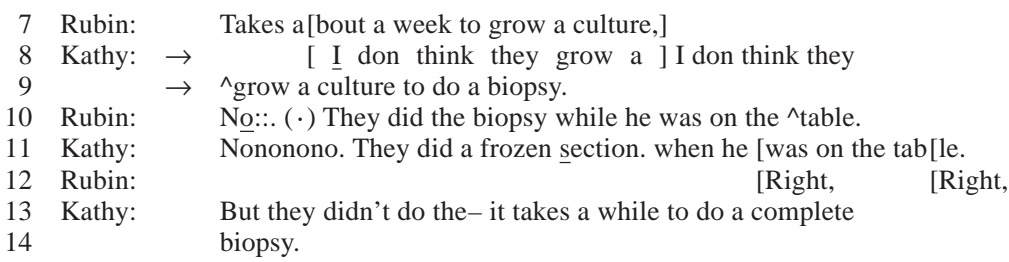

At 25:8, Kathy is (delayedly) taking issue with Rubin's assertion at line 2. She begins in overlap with Rubin's talk already in progress; but the slightly overloud first word of her utterance seems to be less a "turn-competitive incoming" than a contrastive stress, which implements the opposition of the talk being launched to a target, i.e. the preceding talk by another. This stress aside, there is not, in the remainder of Kathy's component of the overlap, any candidate that appears to reflect an orientation to another's talking at the same time. But on resolution of the overlap, Kathy recycles her turn from its beginning - getting it said in the clear, free of possible compromise by simultaneous talk. Notice is here taken of the overlap, and remedy is addressed to its possible consequences, in an exchange in which Kathy is the ostensible agent of the overlap's initiation.

Just as parties to overlap may register its occurrence while treating their own turn as in need of reparative action or not, so also they may register the overlap and attention to the OTHER's turn - at times showing it to be robustly grasped, and at other times treating it as in need of repair. Ex. 26 is drawn from the interview/ confrontation between television interviewer Dan Rather and then-Vice President George Bush, introduced in note 28. Rather has been leading up to a question when Bush preempts it with an "answer" concerning the Iran-Contra controversy:

(26) Bush/Rather (from Schegloff 1989:232)

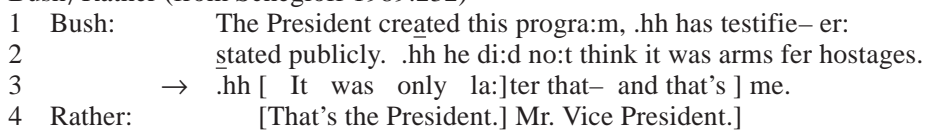

Note here that Rather has responded (at line 4) to Bush's ostensibly complete assertion at lines $1-2$ by attributing the described position to the President - and, by contrastive implication, NOT the Vice President. This response turns out to be in overlap with a further increment to Bush's turn (26:3). As Bush appears to be emerging into the clear (at la:ter, during which Rather's turn reaches possible completion), he cuts off his turn-so-far - in just what would be post-resolution position, were it not for Rather's unprojected addition of the address term ( $M r$. Vice President $)^{37}$ - and demonstrates the unimpairedness of the overlapped talk of his interlocutor by responding to it in a manner that preserves the format (Goodwin \& Goodwin 1987) of the turn to which he is responding (That's the President ... and that's me).

Such a move - attesting to the robustness of the other's component in the overlap, on its completion - is not uncommonly followed by speakers' recycling of their own component of the overlap. Even if that component had not been 
impaired by the overlap itself, it has now been impaired by the self-interruption to respond to the interlocutor. In resuming it, its previously articulated beginning is re-said. Drawing again on the Bush/Rather episode, a few minutes after the previously cited exchange, Rather has led up to a question by presenting ostensibly contradictory claims about the Iran-Contra affair which he now asks the Vice President to reconcile:

(27) Bush/Rather (from Schegloff 1989:231, simplified)

1 Rath: $\rightarrow$ =Now [how do you-How] do you reconc-] I have sir]

2 Bush: [ Read the memo.] Read the memo.] What they:: ] were doing. =

3 Rath: $\rightarrow$ =How: can you reconci:le that ...

Note that as Bush finishes a second saying of his urging that Rather read the relevant memo - with his turn (and the overlap) at projectable possible completion - Rather cuts off HIs turn-so-far at the projectable post-resolution phase. ${ }^{38}$ He displays the robustness of Bush's competing turn, and of his own grasp of it, by responding to it, and doing so with the pro-term have which, in effect, is designed to presuppose it (I have, sir). Having addressed the robustness of his interlocutor's part in the overlap, Rather then addresses his own, showing himself to be restarting the same utterance by composing it with the same words. ${ }^{39}$ As noted, this is the canonical order when both operations are to be implemented out of a self-interrupted utterance: first addressing the interlocutor's utterance, then redoing one's own (for another example, see the data examined in Schegloff 1997a).

While such practices clearly register the occurrence of something special in the just-preceding talk, the stance they take up demonstrates that the overlap has not subverted the parsability of the talk of at least one of its participants (unless, of course, the "responsive talk" reveals its speaker to have a problematic understanding of what is being responded to). Whatever disruption the overlap represents in the allocation of opportunities to talk, in the competition for the turn position etc., it is shown NOT to have subverted the capacity of the talk to convey what was being said in it, or to implement the action(s) being prosecuted through it (even if the party showing this goes on to propose the possible impairment of his own talk by repeating it).

But the stance taken up by one or more of the parties at post-resolution may instead be to underscore just such a subversion. This is accomplished by one of the parties to the overlap, just at or after its resolution, initiating repair on the OTHER's talk in the overlap. The degree of problematicity of the impaired talk is registered by the practice used to initiate the repair. Such practices are implemented by so-called "construction forms" of differing "strength," varying in the degree of grasp they show their speaker to have of the problematic talk (Schegloff et al. 1977).

For example, a repeat or partial repeat of the trouble-source helps to pinpoint just what in the preceding talk was problematic, and what that talk was heard and understood to be; and it invites confirmation or correction of that provisional 
"grasp." A construction form like huh?, however, embodies the stance that all that was understood was that the other said something, but none of it was grasped (i.e. heard and understood) well enough to attempt a version of it. It treats the trouble-source as deeply problematic, and the sources of the problem as therefore having been more sharply consequential. When this is done in the aftermath of an overlap, the source most suspected is the overlap itself. Here we examine just a few exemplars of each of these post-resolution, repair-implemented stancetakings toward the overlap; one marks lesser impairment, and the other (and more common) one marks greater impairment.

First, partial repeats. ${ }^{40}$ In ex. 28 , Bee has called Ava; these are former close friends who have not talked for a while. In the very first exchanges, Bee senses the possibility that Ava is "upbeat," and she undertakes to check that out:

(28) TG, 1:16-24

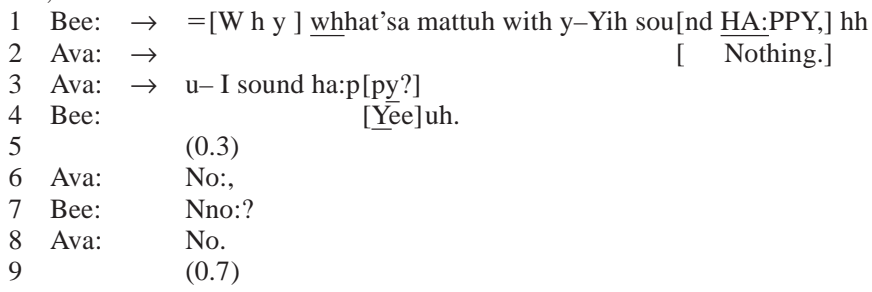

Bee's utterance at 28:1 is composed of several turn-constructional units, each of which makes some response relevant (discussed in Schegloff 1996a:66-67). As Bee is producing the third of these TCUs ( yih sound happy), Ava is responding to the second one (at 28:2, nothing as a response to whatsa mattuh with y[ou]). The result is an overlap. Just after the resolution of the overlap, Ava initiates repair on the overlapped part of Bee's turn with a context-adjusted repeat of it - replacing you with $I$, given the change of speaker - showing that she has achieved a candidate grasp, but one which she offers as in need of confirmation. ${ }^{41}$

In ex. 29, Hyla and Nancy (both college students in the mid-1970s) have tickets to go to the theater later that evening to see the play The Dark at the Top of the Stairs, on Hyla's initiative. Nancy has asked how Hyla comes to know of the play. Hyla has been recounting the story, and has reached a point where she had decided not to go to the play.

(29) Hyla, 6:1-14

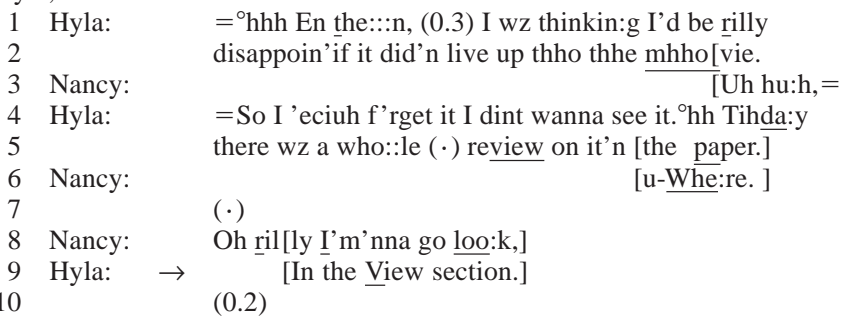


11 Nancy: $\rightarrow$ In the [Vie:wi

12 Hyla: $\quad\left[{ }^{\circ}{ }^{\circ} \mathrm{hh}\right.$

13 Hyla: Yeh- buh I don' wantchu tuh read it.

14

$(\cdot)$

The overlap here is engendered in a fashion similar to the preceding extract. Nancy is tracking Hyla's utterance at 29:4-5 in the course of its production, and she projects whole review on it as the turn's completion; she then pursues the matter by asking where, even as Hyla is adding the source of the review to the end of her turn, thereby constituting an overlap with Nancy's question.

Note that in post-resolution position, after a momentary gap of silence which itself constitutes a hitch BETWEEN turns (it momentarily delays the progressivity of the sequence), each speaker shows that she heard, unimpaired, what the other had said in the overlap, in that she produces an appropriate next turn for it. Nancy determines to consult the review, now that she has been told where to find it; Hyla shows that she heard Nancy's question, and responds with a more finely detailed answer. As each does so, they once again collide in a same-turn position. ${ }^{42}$ This time, however, Nancy takes a different stance; the overlap has somewhat impaired her uptake of Hyla's talk in it, although only mildly, as she shows by offering her grasp for confirmation (29:11). (Note further that with her confirmation, 29:13, Hyla's injunction to Nancy not to read the review offers evidence that she has unproblematically grasped Nancy's part in the preceding overlap.)

But the stances taken up for display by initiating repair after resolution of an overlap are more commonly less benign. In failing to register anything more than that the addressee had said something, the party initiating the repair with huh? may be displaying a range of positions - from "having failed to grasp despite a best effort," to "having disattended or only partially attended this speaker from the outset because of involvement in an exchange with another." ${ }^{43}$ In any case, the stance taken is that the viability and efficacy of the talk by the other in overlap has been seriously compromised.

In ex. 30, Mike is angling to obtain what he takes to be fish aquaria belonging to Vic, currently unused:

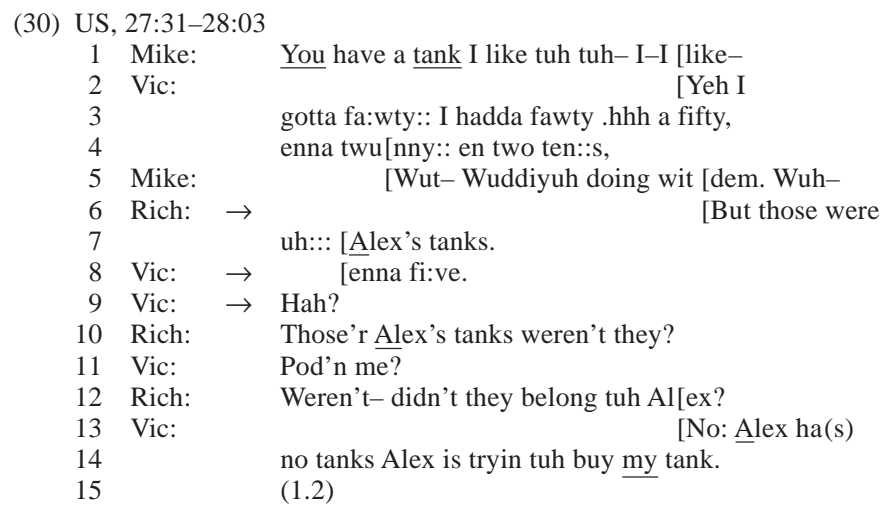


Here the sequence is being prosecuted by Mike and Vic. Mike's utterances at 30:1 and 30:5 are a clear display of interest, and they constitute something of a presequence projected to lead to a transaction. ${ }^{44}$ In response to the first of these, Vic not only confirms Mike's supposition but also details his holdings in an utterance constructed in the canonical form of a three-part list (Jefferson 1990); enna (at 30:4) marks the next item as the third and final item on the list, and thereby as possible turn completion. ${ }^{45}$ In keeping with this projection, Mike starts a next turn, in effect his pre-offer or pre-request - only to find Vic adding to the list. At a point where Vic's now incremented turn appears complete, and where Mike's pre-offer is about to be complete and perhaps to initiate a transaction, Rich enters to call Vic's ownership of the aquaria into question (30:6). As he does so, Mike begins to add another unit to his apparently completed turn, thereby extending the overlap with Rich; and when Mike then drops out, there is a post-resolution hitch in Rich's turn ( $u h::$ in line 7). Into that breach steps Vic with yet another increment to his list of fish tanks, now overlapping the remainder of Rich's challenge to his ownership. After completion of that overlap, Vic takes the stance that Rich's talk in it is deeply problematic, with a repair-initiating Hah? ${ }^{46}$

In ex. 31, Hyla has confessed to Nancy that she telephoned a boyfriend in another city from whom she has not heard for a while, but she hung up as soon as he answered the phone. Nancy has asked why.

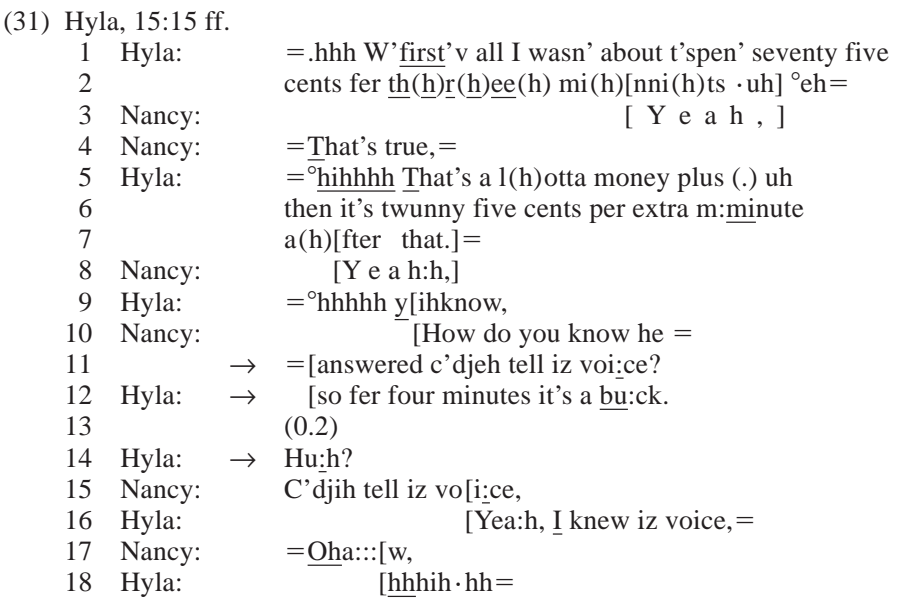

Hyla takes the tack that it was all a matter of expense. By 31:7, her turn seems possibly complete, and Nancy chimes in with an agreement token (31:8) overlapping its final words. Though Hyla's deep in-breath (31:9) might be thought to betoken a substantial turn to follow, Nancy intersects it with a differently focused inquiry (31:10-11). At the first indication that it is in fact differently focused, at the word he at 31:10 - up to that point, the turn-so-far could be more on the matter Hyla has been speaking to - Hyla goes ahead with the talk which her deep in- 
breath had foreshadowed, which is a summary product of the calculations of cost that had preceded; and this fully overlaps the second turn-unit in Nancy's turn. Here again the two of them end virtually simultaneously, engendering a gap of silence, which Hyla marks (31:14) with an aftermath display of the impaired status of Nancy's part in the overlap.

This is, of course, a contingent outcome; Nancy had AS GOOD GROUNDS for breaking that silence, and with such a repair initiator, as did Hyla. Some of what is going on in the (0.2) silence at 31:13, then, has to do with working out who will act there, and how. Now it may be noted that the two utterances that compose the overlap involve, respectively, one that continues what was ongoing in the prior talk, and one that embodies a new departure (albeit not unrelated to the preceding). The repair initiation is done by the speaker of the "old" to the speaker of the "new." This was also the case in the preceding extract. ${ }^{47}$

Note as well that this repair initiation has the proximate consequence of promoting its RECIPIENT's talk as that which will occupy the immediately ensuing spate of talk - a consideration which, we have already noted, can be strategic in shaping the parties' conduct within the trajectory of the overlap itself. This is true quite independently of the differential relationship of the two overlap components to preceding talk. For example, in ex. 32, Shane and Vivian are a student couple hosting another such couple, Michael and Nancy, at a chicken dinner, which is eaten around a coffee table on the floor. After a lull in the conversation, Shane and Vivian start virtually simultaneously, and each persists to turn completion.

(32) Chicken dinner, 22:15-24

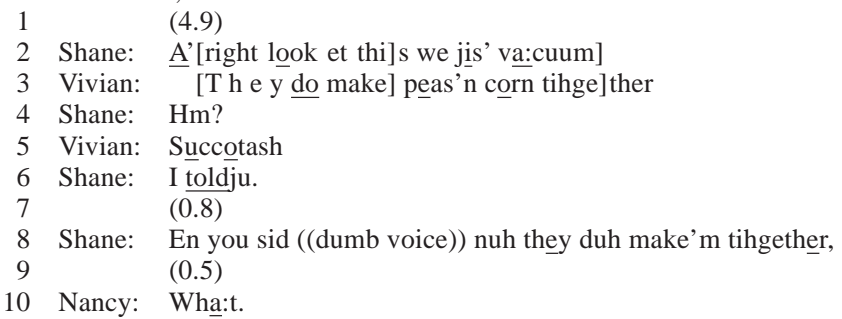

Shane's turn (32:2) takes notice of the mess that has been made of the apartment; Vivian's turn concedes Shane's apparent vindication in an earlier disagreement (not in this conversation) about whether peas and corn are prepared together as a vegetable dish (32:3). Neither topic continues the just-preceding talk; but the turn at which the repair-initiator (32:4) is targeted is thereby afforded an opportunity for extension into the ensuing talk. Note that not only Vivian and Shane pursue it; Nancy is prepared to do so as well.

But this also is a contingent outcome; the overlap component targeted by repair initiation does not always get extended thereby, even when it is topically the 
more closely related to preceding talk. In ex. 33, a family is starting dinner; the mother/head of household has expressed wonder that her adult son, Wesley, had gone jogging that evening (apparently in spite of the heat), and he has asked her whether she had gone jogging as well.

(33) Virginia, 2:30-3:16

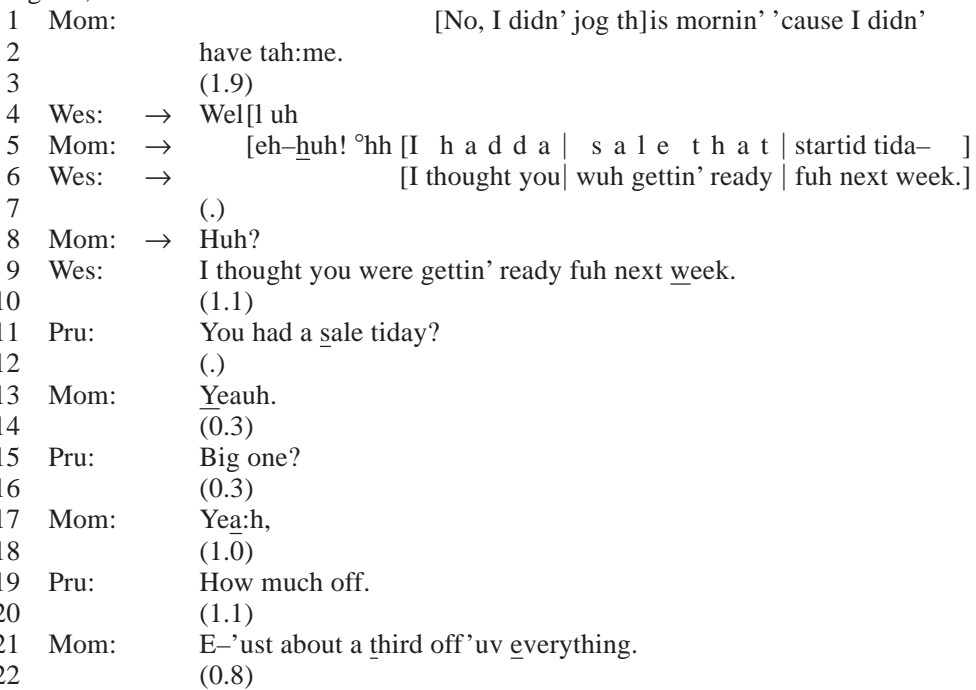

Two observations are in point here. First, although Mom initiates repair (33:8) on Wesley's part in the preceding overlap (33:6), and he responds (33:9), nothing further is made of his talk following the repair. Instead, it is Mom's component of the overlap (33:5) that gets addressed (33:11), after a longish gap of silence is allowed to pass in which no talk is directed to Wesley's prior utterance. Second, in this instance (unlike the earlier ones above), the speaker of the overlap component that is MORE of a departure from the prior talk initiates repair on the talk that is in greater continuity. In the face of this strong impetus to stay on the earlier theme, the new direction of talk actually gets taken up.

If sustained as the preferred practice in further research, the upshot of these ways of proceeding would be to indicate a general tilt to promote a forward movement of the interaction to new topical and action developments.

However, my concern in this section has been with the recurrence, within the immediate post-overlap resolution environment, of displays by one or another party of how the overlap figured for them in the interactional dynamic of the moment. One resource in these displays is the indication that the overlap represented a substantial disruption of the interaction - one which necessitates repair of the talk of one or the other component of the overlap, or both. This can itself serve as an ingredient in quite separate and more general issues for the talk: namely, in what direction it is to be pursued next - now. ${ }^{48}$ 
Of the constraints earlier imposed on this undertaking, several have now been met.

(a) Some account has been offered of how it comes to be that most overlaps are very short and are resolved very quickly, and of what "very quickly" means.

(b) Some account has been offered for how it is that some overlaps come to be rather extended, and what the import of such extension may be for the parties to it.

(c) Some account has been offered for the presence in a great many overlaps of considerable "disfluency" - hitches and perturbations in the production of the talk - and grounds have been put forward for understanding these as practices of conduct rather than as behavioral casualties of conflict or of processing overload (though the two are not necessarily incompatible).

(d) The account that has been offered can be brought to bear on the detailed analysis of single instances of overlap and the trajectory of their developmental course; it also provides resources for characterizing and understanding some robust observations about aggregates of instances of overlap.

(e) The account that has been put forward describes a set of practices which address, on the one hand, formal contingencies of turn-taking, turn organization, turn transfer, and the miscues to which they are vulnerable, and, on the other hand, practices which are capable of accommodating, serving, and displaying elements of the whole universe of other practical and interactional exigencies and projects to which parties to interaction are attending and on which they are acting in the turns organized by a turn-taking organization.

It remains to show how this organization of practices for the management and/or resolution of overlap is related to the turn-taking organization without which it has no rationale and is essentially inconceivable. ${ }^{49}$

It has been possible until now to address the practices of simultaneous talk without reference to the particulars of the turn-taking organization as we understand them. However, it is not possible to explore the relationship between the two without at least a brief sketch of that model of turn-taking organization. This is true because it now appears that the practices of overlap resolution constitute an indigenous element of the turn-taking organization - one that remedies several underspecifications in our previous account of that organization, and one that provides a solution to otherwise anomalous products of that organization.

SSJ described the turn-taking organization as composed of two sorts of "resources," plus a "rule set" in which they were implemented and, as it happened, integrated. One resource was a "turn-constructional resource," and was composed of a set of types of units of talk (called "turn-constructional units," or TCUs) which could, on some occasions of use, be recognizable as themselves constituting a possibly complete turn. Units such as sentential, clausal, phrasal, and lexical ones (not ANY word in ANY context, but some - like hello, no, why, and others, including some formal classes of words such as "words from a preceding turn by another" - had a feature that seemed critical, namely "projectabil- 
ity": the capacity to project for a hearer more or less what it would take for the talk-unit then in progress to be possibly complete. Such a projection could, of course, be confirmed or TRANSFORMED by any next bit of talk out of the speaker's mouth, or any talk-related other conduct (gesticulation, facial expression, posture etc.)

The second resource was a "turn-allocational resource," composed of various sorts or classes of ways in which the opportunity to produce a turn at talk could get presented to, or actuated by, a participant. These included a class of ways by which a current speaker could select someone to talk next, and a class of ways by which participants could claim for themselves the opportunity to produce a turn. We proposed that the two types of turn-allocational practices were "ordered," the self-selecting ones being (on the whole) invocable or institutable only when the other-selecting ones had NOT been employed. This ordering was the product not of the turn-allocational resource itself, but of what appeared to be the ordered set of "rules" or "practices" by which the two resources were integrated, ${ }^{50}$ an organization by which parties to a conversation could manage transition from one speaker to another. By "manage transition," I mean both "effectuate" AND "bypass," but I mean also to specify analytically WHERE "bypassing" has been done if one speaker turns out to continue talking.

This set of practices provided the following:

(i) For any turn, at its first point of possible completion (i.e. the first possible completion of its first turn-constructional unit), if its speaker had selected someone to talk next (e.g. by asking someone a question), then that current speaker should stop at that point, the one who had been selected should begin a next turn there, and no other participant should begin a next turn there.

(ii) If, by contrast, at that first possible completion, the current speaker had NOT selected someone to talk next, then any other party COULD self-select and begin a next turn, with the first one to do so - the "first starter" - getting rights to that turn slot. (Note here the optionality of this possibility as compared to the normatively obligated character of the preceding option.)

(iii) If, at that first possible completion, the then-current speaker had not selected a next speaker, and no one else had self-selected to take the turn, "then" (to cite the wording of the text of the article, 704), "current speaker may, but need not continue, unless another self-selects."

There was more to the turn-taking organization, especially a provision for its recursive operation (i.e. if the last of the aforementioned options had been realized); but that is not relevant to the present concerns.

Built into this organization of practices are several "rounds" of operation or application. Some of its parts include provision for other aspects of their operation, i.e. second-order practices. Several of these may be mentioned here.

Practice (ii), it may be noted, provided for self-selection by any party if the current speaker had not selected a next speaker. But it was recognized from the outset that this was not enough - that this provision could be exercised by more 
than one participant, yielding a result at variance with the very feature "one party at a time" which the turn-taking organization appears designed to support in the first instance. More than one participant might be oriented to self-selection; which self-selector would get the turn?

The solution to the problem of more than one party being a potential claimant to a next turn provided a SECOND-ORDER ORDERING in the face of the possibility of multiple self-selection: THE FIRST ONE TO START gets the turn. This solution is of a type that specifies a particular CLASs of "winner": the first one to self-select. The main appearance of the operation of this practice in actual talk does not involve several speakers talking at once - for by virtue of one self-selector having already begun, other "intending" self-selectors would withhold talk because they were not the first. The first self-selector would, therefore, ordinarily be the ONLY one.

But this solution to the "problem" of multiple self-selection for next-speakership is only partial. Once we recognize the possibility that more than one might selfselect, we must also face the possibility that more than one will do so AT THE SAME TIME. Indeed, later in the article (SSJ, 707), exemplars are given of precisely this - multiple self-selectors simultaneously trying to be earliest starters after possible completion of a just-ending prior turn. How, then, did the rule-set provide for SIMULTANEOUS multiple self-selection for next turn? Who gets next turn if both start at the same time? The article does not say. Its solution can NOT be "first starter goes," because its problem is the product of precisely that specification. The solution, it appears, is not at all that TYPE of solution - not a solution that provides for who in particular should succeed, or what class of participant (like "first starter") should get the turn. Here, as we shall see, the overlap resolution device seems to fill the gap.

A similar underspecification may be found in the last practice cited and quoted precisely above. It says that, if no one has been selected as next speaker, and no one (other than then-current speaker) has self-selected, then the one who had been the speaker up to the possible completion can self-select to continue, "unless another self-selects." AND WHAT THEN? What if a just-now speaker DOEs selfselect to continue in the absence of anyone else making a move to talk - only to find, as he or she does so, that another has self-selected after all? What happens if that circumstance arises? Who gets the turn then, if that "unless" comes to pass? Here again the model, as previously described, is silent; and this is the other "underspecification" in the set of practices to which I am calling attention. ${ }^{51}$ There is a gap here, a failure to provide a resolution for certain contingencies which an organization of this sort should be expected to provide - not least of all because the organization itself, by the practices otherwise described, engenders them. The answer is not, again, a determinate answer to "who" - neither a particular "who" nor a class from which the "who" is selected.

The solution to these underspecifications is of a different sort. It does not specify who the "winner" is (as in "first starter"); it provides A PROCEDURE FOR 
ARRIVING AT A SOLUTION - A PROCEDURE FOR THE PARTIES to arrive at a resolution. ${ }^{52}$ That solution is the provision, as part of the turn-taking organization, of a mechanism by which two such parties, finding themselves talking simultaneously, can work out which of them will get the turn. They can do so in a fashion sensitive not only to the formal mechanics of the turn-taking organization which have momentarily engendered a possible impasse; they can do so in a fashion which also allows all parties to incorporate and display the stance they mean to take in view of that moment in the interaction - its content, its issues, its engaged participants, its context, its priorities etc. - and allows them to adjust that stance moment by moment, beat by beat, as the other's stance is revealed as well. Thereby a formal organization is made exquisitely sensitive to the substantive and interactional contingencies of the moment, in a fashion thoroughly furnished by the parties, just then, just there.

In these respects, the overlap resolution device I have been describing is of a piece with the turn-taking organization of which it now appears to be a component (compare SSJ, 724-27): ${ }^{53}$

(a) It is locally organized, operating here not turn by turn - for it is just the turn that is being contested - but beat by beat.

(b) It is party-administered, delegating the outcome not to any formal rule but to the conduct of the parties involved in the occasion.

(c) It is interactionally managed and recipient-designed; it is precisely in responses to one another's relevant identity and interactional moves and stances that an outcome is reached.

\section{O N C L US I O N}

I have tried to formulate a set of empirical observations and analytic constraints to which an account of the management of simultaneous talk should be responsible; and then to offer an account of a set of practices deployed by parties to conversation which accounts for those observations, or is compatible with them, and meets those constraints. It turns out that this set of practices, an overlap resolution device, in effect resolves a number of otherwise troublesome underspecifications in the model of turn-taking proposed by SSJ some years ago. Accordingly, it seems appropriate to TAKE THE SET OF PRACTICES THAT COMPOSE THE OVERLAP RESOLUTION DEVICE TO BE A COMPONENT OF THE TURN-TAKING ORGANIZATION IN THE FIRST INSTANCE - albeit a second-order component designed as a resource for the resolution of trouble engendered by the turn-taking organization itself, or imposed on it by parties' pursuit of such other interests, projects, and commitments as talk-in-turns can be a resource for achieving. These are the conclusions most relevant for students of the workings of talk-in-interaction as a topic in its own right.

Finally, as suggested at the outset, this essay has offered resources to those in any discipline who seek analytic tools for the detailed examination of real-world 
talk-in-interaction suitable for the analysis of actual singular episodes of talk. Here I add only that these resources are not relevant only to the analysis of overlaps per se, or to analyses focused on overlap or interruption in particular. Rather, they are relevant to any talk in which overlap or "interruption" occurs, or COULD occur which constitutes a very large proportion of all talk-in-interaction. This is so because few of the phenomena implicated in the management of overlap have that as their sole deployment, and few invite interpretation - whether by interactional coparticipants or by external observers and analysts - solely by reference to overlap. Various of the hitches and perturbations lend themselves to interpretation as evidencing (such vernacular interpretations as) "self-censorship" (e.g. cut-offs), or "cautious hesitation" (e.g. sound stretches), or "nervousness" (e.g. cut-off with repeat); pursuing such lines can lead to flights of interpretive and analytic fancy ... and much waste of time. It is therefore useful to be alert to the possibility that any of these occurrences, if found in the immediate aftermath of an overlap's resolution, invites in the first instance treatment as a "post-resolution hitch" (see above). If the hitch is a sudden increase in volume, it may implement an effort to interdict an overlap's onset - a possibility that is even more important to be attentive to, because, if the effort is successful, there may be no overlap at all to alert the investigator to what is going on. ${ }^{54}$ In none of these scenarios does recognition of implication in overlap-related talk exclude additional (or alternative) accounts, of course; but such recognition can relieve the onus which interpreters and analysts often feel to determine the "significance" of an observable, describable, deployable element of conduct in interaction. Because so many of the "moves" used for competitive production have alternative import if produced in solo production, this problem is endemic to talk-in-interaction and its analysis. If there are resources here for those who want to understand what is going on in spates of talkin-interaction, these resources are not overlap-specific - even if they do concern overlap resolution, and its place in turn-taking, and whatever turn-taking serves.

\title{
NOTES
}

\begin{abstract}
* The work reported here was done for the most part in the early 1970s. Some of it was presented at the Linguistic Institute, University of Michigan, Ann Arbor, in the summer of 1973. The only parts previously appearing in print were the text of a public lecture at the Institute on "Recycled turn beginnings," published as Schegloff 1987a, and a rudimentary version of some of what follows below (Schegloff 1987b). Subsequent versions of other parts were delivered in a variety of venues, including Linguistics and Sociology Colloquia at the University of California campuses at San Diego (1973) and Santa Barbara (1975 and again in 1996), the 3rd Annual Conference on Special Problems in the Social Sciences at the University of Konstanz (West Germany), June 1975, the annual meeting of the British Sociological Association in Spring 1979, the 1987 meetings of the American Anthropological Association (published as Schegloff 1995a), and the 1990 meetings of the Speech Communication Association in Chicago. Aspects of those presentations and lectures in my courses have informed published work by others (e.g. Hopper 1992, Chs. 5-6; Moerman 1988:19-30, 188, n. 15).

I have for more than 25 years withheld an extended and formal writeup of this work in the hope of expanding the data base in which it was grounded, especially with respect to video data, and in the hope of addressing the substantial and continually growing literature of this much focused-on topic. It now appears unlikely that I will be able to realize either of these hopes, so I offer here a version of
\end{abstract}


my take on simultaneous talk and its resolution, substantially along the lines which I have been teaching and otherwise delivering orally since 1973; elsewhere I explore the bearing of this work on topics such as "interruption."

In the years both preceding and following publication of the 1974 paper on turn-taking, my colleague Gail Jefferson has been working at many of the same problems and types of materials as are the focus of this project of mine; but, for various reasons, we have worked essentially independently. A paper delivered by her at the 1975 meetings of the American Anthropological Association, and subsequently circulated under the title "Sketch: Some orderly aspects of overlap in natural conversation" with both our names attached (Jefferson \& Schegloff 1975), represented a gracious effort on her part to present a take on the topic as it had emerged in her own work, but which she understood to be shared between us. (It is forthcoming under her sole authorship in Lerner 1999b.) In a great many respects our findings are quite similar, but what I offer here, I offer only as my own understanding of the matter. It has benefited over the years from comments from many students and colleagues, most recently Steve Clayman, Paul Drew, John Heritage, Gene Lerner, Candace West, Tom Wilson, and Don Zimmerman; where their contributions have been appropriated, it has mostly been without further notice.

Parts of this work have also benefited from research on other-initiated repair supported by the National Science Foundation under Grant No. BNS-87-20388. Final manuscript preparation was undertaken while I was the grateful beneficiary of a Guggenheim Fellowship and a Fellowship in Residence at the Center for Advanced Study in the Behavioral Sciences, Stanford, California, under support provided to the Center by the National Science Foundation through Grant \# SBR-9022192.

${ }^{1}$ The line taken in SSJ has, of course, not gone uncontested in the scholarly literature - largely, though not exclusively, by anthropological colleagues, and largely, though not exclusively, by invoking cultural variation, whether based in ethnicity, gender, or some other type of social formation. One point of contention has been the treatment of "one at a time" as a central point of reference for the organization of turn-taking. Various "mismatches" have compromised the fruitfulness of the exchanges, however. Edelsky (1981) and Phillips (1976:92-94) are apparently dealing with data drawn from meetings, which are treated by SSJ as embodying a different "speech-exchange system" than does conversation - comparable with it, but structurally different, and therefore ill-suited grounds for contesting an account of conversation. (This caution, by the way, may also apply to Smith-Lovin \& Brody 1989, whose "task-oriented groups" of six participants may well have organized their sessions in a meeting-formatted speech-exchange system.) Nor is it clear in Edelsky's account that a single interaction is involved rather than several; with as many as eleven participants (1981:385), the meetings she studied were singularly vulnerable to schisming (SSJ 1974:713-14, Egbert 1997). But SSJ's claim was that turn-taking is organized by reference to one-speaker-at-a-time IN A SINGLE CONVERSATION. Reisman's account (1974) of “contrapuntal conversation" in Antigua leaves it unclear whether these practices for organizing talk are proposed as characteristic for particular activities, genres and/or occasions (1974:111) or as being more general in their provenance. (This is important because, as will be seen below, the SSJ account is not merely compatible with particular activities departing from "one-at-a-time"; it fosters and contributes to that view.) Most important of all, however, is that virtually none of these accounts provides the sort of repeatably inspectable data on which SSJ is based and which allows an empirically based, detailed judgment on the issues that have been raised above and others (though some anthropologists were grounding analysis in such data at that time and before, e.g. Moerman 1977, 1988). In this respect, work like that reported by Brown 1996, based on audio and video recording in mundane, unspecialized settings in a Tzeltal village, promises to allow these issues to be explored on more solid ground (and see Duranti 1997 on ceremonial greetings in Samoa; and M. Goodwin 1990 on African-American children, or M. Goodwin 1997 on "by-play" in a middle-class white setting). It should be said, however, that nothing special rests on the "one-at-a-time" proposal. Should a compelling demonstration of a different way of organizing participation in conversation be provided, it would allow us to seek a more general account that could subsume both one-at-a-time and its alternative(s) as special cases. To do this, however, will require particular alternative proposals and the data on which they are based: If not one-at-a-time, is it ALL-at-a-time? Some other limited number? Or are there no constraints or describable practices at all, as apparently claimed by Reisman (1974:113-14)? This last proposal especially requires an affirmative demonstration with repeatably inspectable data, or else it elevates the ABSENCE of a finding - potentially a failure of analysis - into a finding, an assertion about the world (and one relied on by others as probative, as in Hayden 1987). Recent work by Sidnell 1998 on Caribbean Creole, grounded in such data, suggests findings quite

Language in Society 29:1 (2000) 
different from those of Reisman. Of course, not all anthropological work has been adverse; e.g., Moerman's analysis (1988:19-30, 188, n. 15), along the lines developed in the present article, bears on an extended overlap in recorded Thai village interaction.

${ }^{2}$ On political settings, cf. Atkinson 1984, Clayman 1993, Heritage \& Greatbatch 1986.

${ }^{3}$ The point of the formulation "co-constructed by reference to one-party-at-a-time" is that, although talk is overwhelmingly designed to REALIZE that feature, it may also be designed to DEPART from it as a practice for implementing specific action outcomes. For example, Jefferson 1973 argued that a recipient may show that something he is being told was already known to him, without benefit of the current telling, by intervening at the first possible point at which the purported "news" is recognizable; and this will be displayed by doing it "interruptively," i.e. while the current telling turn is still in progress and has not yet implemented a full telling (see also Sacks 1992:I.642-43). Lerner (1999a) describes the coordinated effort that several parties may make to say some part of a turn-inprogress "together," i.e. in unison - at least in some instances, apparently as a collective demonstration that they all convergently know what is to be said, without being told it. Such outcomes are co-constructed by reference to one-party-at-a-time, even though they are realized through designedly simultaneous talk. It is not entirely clear whether these observations have any bearing on Coates's account (1988) of talk among (some) women, or whether what is involved is a systematic lack of relevance for them of constraints on number of speakers.

${ }^{4}$ Cf. Jefferson \& Schegloff 1975 for an early, partial formulation of such an account.

${ }^{5}$ The rest of this preliminary section is a revised version of Schegloff 1995.

${ }^{6}$ For a carefully developed demonstration that "assessing" is an activity which may specifically be organized to occur concurrently with the very talk activity being assessed - yielding extended, noncompetitive overlap - see Goodwin \& Goodwin 1987, 1992 b.

${ }^{7}$ Choral production itself is not helter-skelter, but is the product of orderly collaborative practices for its production; much more can be said about the temporal and sequential organization of these activities, other than that they are done in concert. There is now ample documentation of the detailed orderliness of laughter (e.g. Jefferson 1985, among many others). Duranti 1997 has suggested that there may be a detailed orderliness in the apparent randomness of at least some collective greetings. See also Lerner 1999a for more on choral productions as concerted (and orchestrated) achievements. So also there may be normative obligations regarding who should lead in collective congratulations or condolences, and who should join in, and when.

${ }^{8}$ Other occasions of simultaneous talk which are neither mandated nor licensed invite special treatment as well, although their proper character cannot yet be specified. For example, co-members of a party (e.g. a couple who are participating in the talk at that moment AS a couple) may come to talk simultaneously because their party has been selected to speak next, but in a fashion that does not specify which of them is to do the speaking. The matter is taken up with empirical materials in Schegloff 1995; in the data treated there, all the overlap is between co-incumbents of a party (spousal couples), and none is between persons from different parties. Although such occurrences have not been subjected to sustained empirical inquiry, they are not infrequent; they are systematic products of a turn-taking organization which allocates turns to parties, but not necessarily among party coincumbents. The issue is further complicated by the frequently contingent and shifting character of the "capacity" or "footing" (though not in the sense of Goffman 1979) in which people are speaking, or about to speak - whether as parties in their own right, or as co-incumbents of a party with one or more others. Whether such "party co-member" overlaps are properly encompassed by the present undertaking, or excluded from it, will depend on what is learned from studying them.

${ }^{9}$ Increases in the number of participants may increase the likelihood of the schisming of the conversation into more than one conversation (and therefore into the overall number of separate conversations and speakers), but not of the number talking simultaneously in any SINGLE conversation (on schisming, see Egbert 1993, 1997).

${ }^{10}$ This aggregate observation can be supplemented by examination of individual cases. For example, in the following extract, two couples are pondering the import of a diagnosis of a mutual friend's illness, which has tentatively been understood as "good news" - namely that rather than "cancer," the friend has a "giant follicular lymphoblastoma." This diagnostic term has just been written down and read so it can be shown to a physician acquaintance, and a light-hearted riddle is posed by one of the company to the others (lines 11-12), who all join in a hubbub of solutionproposals. Although this sounds like a chaotic babble of voices, it may be observed that, as soon as three come to be talking, at least one drops out to reduce the number to two: 


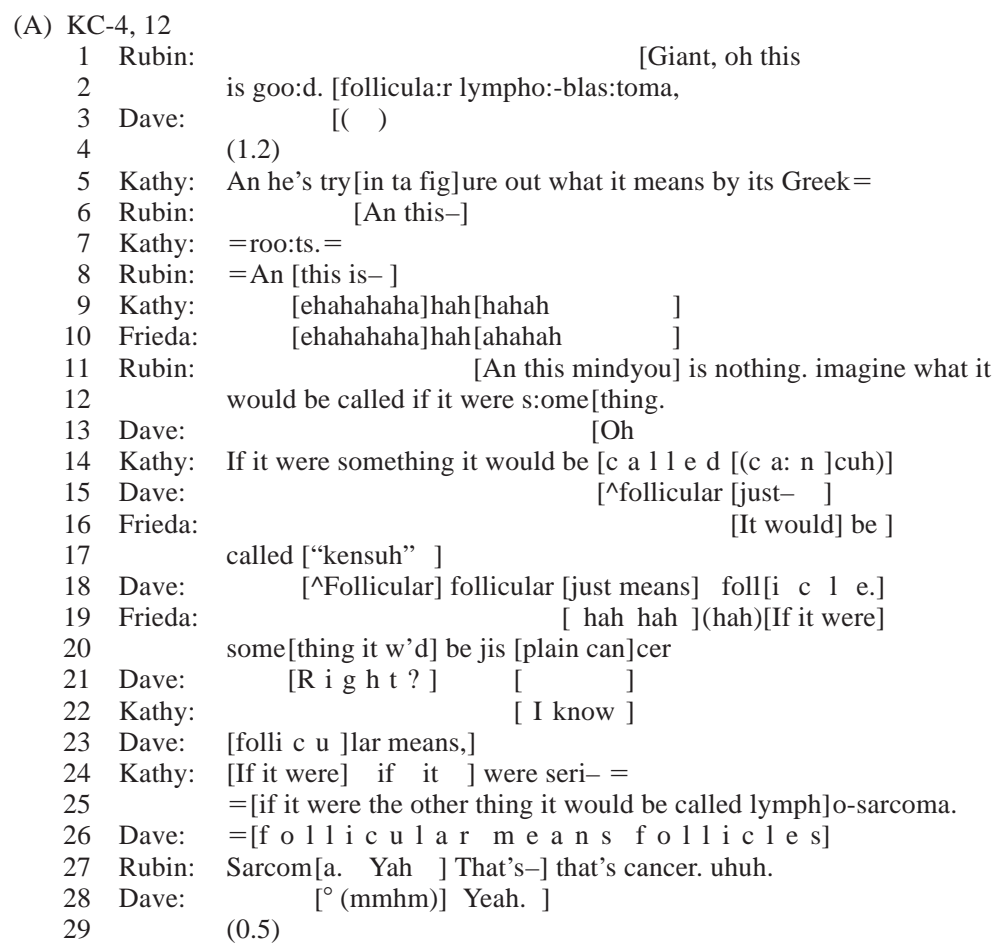

For example, with Frieda's entry at A:16, three are talking, but Dave's withdrawal reduces it to two (and Kathy's arrival at possible completion reduces it still further). Note as well that both Dave's and Frieda's start-ups may be predicated on the projected completion of Kathy's turn. Frieda's in particular may be designed as an alternative anticipatory completion (Lerner 1996) of Kathy's turn, and thus not competitive with it; and this may contribute to Dave's withdrawal.

Readers are invited to access the audio of this and virtually all the data extracts in this article, in a format suitable for most platforms, on my home page, which can be addressed at $\langle$ http://www. sscnet.ucla.edu/soc/faculty/schegloff/overlap/ $\rangle$. Should this web page cease to be available, readers should contact me directly or search the California Digital Library at 〈http://cdlib.org $\rangle$.

${ }^{11}$ Because of the complexity of the patterns of overlap here, I offer some guidance on the reading of the transcript. I presume familiarity with the convention that brackets mark coincidence of the points on lines that they connect: left brackets mark the simultaneous onset or continuation of the utterances at the point of placement; right brackets mark simultaneous arrival of the preceding talk to that point. Equal signs (=) mark here the no-break continuation of a speaker's utterance which has been deployed over two or more lines (e.g. Vic's talk at 2:8-10 or 2:13-15, or James' talk at 2:14-16, or Mike's at 2:18-19). Thus, at 2:17, Mike comes in on the already overlapping talk of Vic and James 2:15-16. After all three speakers have stopped, Mike starts "in the clear" at 2:18, but has James come in on his talk at 2:19-20. In turn (so to speak), Mike comes in on James's talk at 2:21-22, and Vic comes in on Mike's at 2:23-24.

Mike and Vic start together at 2:26-27, terminally overlapping James's talk at 2:25. Mike then comes in on Vic's talk at 2:28-29, and then again at 2:30-31. At 2:32-33 James and Mike start simultaneously, Mike's turn then continuing at 2:35 and 2:37, with intermittent overlaps by James.

12 One last point needs to be mentioned concerning these three "configurations." I have offered them here to characterize alternative possible forms that simultaneous talk can take. Independently, Lerner (1987:213-15) has formulated quite similar patterns in characterizing the contexts for collaboration between several participants in producing a turn at talk. Lerner has found that aspects of the 
form which a collaborative completion of another's utterance is given, and aspects of how such a proposed completion is received, vary with the "directionality" of the first part of the turn, and of its candidate completion by another - where "directionality" refers to just such matters as are summarized by the "configurations" diagrammed in the present text. Something robust is afoot here - something real for those who share a turn's space, whether by competing for it or combining to produce the talk in it. What is central or peripheral for studying simultaneous talk may need to be assessed differently for studying other joint occupations of a turn's space. For another use of a conversational device - namely [cut-off + identical restart] for dealing with different but related contingencies of talking in interaction, namely "turn launching" contingencies - see C. Goodwin 1980 and Schegloff 1987a.

${ }^{13}$ That is, an interruption or blockage of the air stream by which sound is made (a "stop"), either by completely closing the vocal cords (glottal), or with the tongue against the teeth (dental), or otherwise obstructing the production of sound.

${ }^{14}$ The listed practices amount to a mobilization of virtually all the facets of prosody or intonation, from the production of sound altogether to its three constitutive facets: pitch, power (or volume), and pace (or speed). For recent accounts of some of these practices in more technical phonetic detail, see French \& Local 1983 (focusing on pitch and volume), Payne \& Wells 1999, and a number of the contributions to Couper-Kuhlen \& Selting 1996. Note that the resources which figure in the practices for dealing with overlapping talk are already "on line" as components of talking per se, and are available for deployment with respect to overlap when relevant.

${ }^{15}$ The sound stretch is not the only one of the hitches and deflections that warrants such a characterization. Cf. Schegloff 1987a for a parallel account of some cut-offs followed by recycling.

${ }^{16}$ The following instance of this orientation may serve as a dramatic exemplar, though it may appear out of place here because no actual overlap occurs in the exchange. Of course, that simply testifies to the efficacy of its deployment in this instance. Because this extract is drawn from a telephone conversation, the pre-turn inbreath is available with greater clarity (both to recipient and to observers) than is often the case. In this call, an absent father calls home, only to be met with an indictment from the child's mother.

(B) David and Robin, 1:1-29

\begin{tabular}{|c|c|c|c|}
\hline 1 & & & Ring rin- \\
\hline 2 & Robin: & & Hello.- \\
\hline 3 & David: & & Ro:bin? \\
\hline 4 & & & (.) \\
\hline 5 & Robin: & & Yeah. \\
\hline 6 & David: & & Hi:: \\
\hline 7 & & & $(0.8)$ \\
\hline $\begin{array}{l}8 \\
9\end{array}$ & Robin: & & $\begin{array}{l}\text { You have one hell of a nerve. } \\
(0.2)\end{array}$ \\
\hline 10 & David: & & $(. h h h h) /($ hhhh $)$ \\
\hline 11 & & & $(0.8)$ \\
\hline $\begin{array}{l}12 \\
13\end{array}$ & Robin: & & $\begin{array}{l}\text { Now listen ta me. = I jus' wanna tell you one thing. } \\
\text { (.) }\end{array}$ \\
\hline $\begin{array}{l}14 \\
15\end{array}$ & David: & & $\begin{array}{l}\text { Yeah? ((Weakly; without lower registers of voice })) \\
(0.8)\end{array}$ \\
\hline $\begin{array}{l}16 \\
17\end{array}$ & Robin: & & $\begin{array}{l}\text { Y'to:ld me on Sunday, (.) that you were coming home on } \\
\text { Thursday. }\end{array}$ \\
\hline 18 & David: & $\rightarrow$ & $\overline{\text { pt. }} \cdot$ hhhhh $=$ \\
\hline 19 & Robin: & $\rightarrow$ & $=Y^{\prime}$ didn't te- wait don't:(.) [inte]rrupt me. \\
\hline 20 & David: & & {$[\mathrm{OK}-]$} \\
\hline 21 & David: & & O:okay, $=$ \\
\hline $\begin{array}{l}22 \\
23 \\
24\end{array}$ & Robin: & & $\begin{array}{l}=\mathrm{Y}^{\prime} \text { didn' tell me how: you were coming, }(1.0) \text { y'could've come } \\
\text { by pla:ne, y'could've come by ca:r, =y'could've been } \\
\text { hitchhiking. }\end{array}$ \\
\hline
\end{tabular}

Robin's utterance at B:12 - a "pre-pre" (Schegloff 1980) - projects an extended telling in which what is to follow next is preliminary to something for which it will prove a resource. It thus claims the floor 
for an extended, multi-unit turn. David's breath at B:18, following the first installment of the projectedly extended utterance, is apparently heard by Robin as a pre-talk inbreath, and hence as potentially pre-onset to overlapping (and interruptive) talk. She self-interrupts the next installment of her utterance to address, and try to head off, this incipient collision - successfully, as it turns out - before resuming the bill of particulars. In contrast to most of the material which we are examining - in which dealing with the overlap is embedded in the talk otherwise being produced, and does not devote differently focused, separate talk elements to the (incipient) overlap - here the ongoing talk is stopped in order to deal with the impending overlap as a discretely focused-on matter. The (incipient) overlap is thus taken notice of in a fully explicit way. We will later return to this theme in the section titled "Overlap aftermath."

${ }^{17}$ French \& Local 1983 have given the label "turn-competitive incoming" to new turn starts which are launched in a fashion prepared to contest the turn space (utilizing high volume and pitch). These pre-onset phase practices could be described as the "defender's" counterpart.

18 The "rush-through" described by Schegloff 1982 - in which a speaker approaching a projectible possible completion of a turn-in-progress moves to interdict another speaker's starting up, by accelerating the pace of the talk and "rushing through" the transition space into the start of a next turn-constructional unit - turns out to be one specification of the overlap resolution device applied in a pre-onset phase implemented through pace modification. The "pre-onset-ness" is, in these instances, furnished not by the particular conduct of another, but by the generic relevance of turn-transition at possible turn completion - a turn-completion which the speaker has projected as imminent. The convergence of the previously described rush-through with this more general account of resources and phases of overlap resolution is quite transparent, however unanticipated.

${ }^{19}$ There is more to be said about the post-resolution phase and the resources deployable there; some of this is taken up in the later section entitled "Overlap aftermath."

${ }^{20}$ A possible POST-POST-RESOLUTION PHASE also merits notice; at this phase, repairs of various sorts may be undertaken on "casualties" of the overlapping talk. The discussion in the section entitled "Overlap aftermath" touches on this possibility.

${ }^{21}$ I am told that Japanese, and perhaps other Asian languages, are currently understood to be organized by "beats" (or "mora") rather than syllables. Whether the beats involved there are the same as what is involved in the present discussion is unclear.

${ }^{22}$ Writing from the viewpoint of developing automatic speech recognition systems, for natural language processing, which are sensitive to how humans actually appear to listen, Greenberg 1997 writes: "Although segmentation at the phone and word level is explicitly built into current-generation ASR systems, there is little evidence to suggest that human listeners segment on these levels ... Listeners appear far more sensitive to syllabic and phrasal boundaries than to those imposed by lexical and phonological criteria" (citing Segui et al. 1990 with respect to syllabic boundaries). Also clearly related to "beat" organization is work on rhythm and rhythmic placement of talk in interaction, pursued along a variety of paths (cf., inter alia, Erickson \& Schultz 1982, Couper-Kuhlen 1993, Local \& Wooton 1995).

An anonymous referee, noting that " 'beat' tends to have a rather specialized meaning of 'strong' or "stressed' syllable," recommends the use of "syllable" instead of "beat" throughout the discussion which follows in the text, especially as "the data which are presented - in which syllables are treated as 'beats' - contain a number of unstressed/weak syllables as well as stressed syllables." I reluctantly decline to follow this recommendation because it is not clear to me that it is the "syllable-ness" of the units to which I am pointing that figures in the practices being described. I must emphasize, therefore, that I am using the term "beat" not in the technical sense of the literature in linguistics, but as a simpler, perhaps even vernacular, term for the syllable-like increments of production by which talkin-its-course (and its silences) is produced.

Still, it is worth mentioning one other sort of evidence that makes the linkage of the "beat" to the "syllable" cogent. In characterizing what occurs at the transition between successive turns, Jefferson (1984a:18) used the term " "unmarked next position' onset" to refer to transition spaces in which a beat of silence is allowed to pass before a next speaker starts a next turn, a trajectory which I have elsewhere termed the "normal value of the transition space"; i.e., the practice for embodying that "simple" transition (and nothing else) is being accomplished. It happens that while incipient next speakers hold off starting a next turn, prior speakers, instead of stopping, continue to talk. If we look to see how much talk fits into the beat of silence left by next speakers before they start next turns, it regularly is

Language in Society 29:1 (2000) 
one syllable. For examples, see Jefferson, ibid., pp. 19-20 (exx. 19-21) and p. 22 (exx. 22-25), only one of which I present here to instantiate the point.

(C) Jefferson 1984a:19

1 Lottie: so I fixed (.) lunch fer the:m en [so: Jêe:ziz I wz really...

2 Emma: [nYeoh

Lottie's turn is projectibly possibly complete at the: $m$, and when Emma holds off starting her next turn for one beat, what "fits into it" in Lottie's continuing talk is the single syllable en. This is what all the instances cited above look like, reinforcing the possible linkage between "beat" and "syllable." I thank Paul Drew for prompting me to explore the convergence with these observations by Jefferson.

${ }^{23}$ In fact, alternating "gaps" and "overlaps" can be a systematically engendered sequence of events - not unlike the pedestrian version in which two persons, encountering one another on a narrow path, choose the projected complementary bypass routes and find themselves again at a stand-off, reproducing the stand-off as long as each reacts similarly to the last one. Ordinarily, of course, this turn-taking characterization of the alternation of more-than-one and less-than-one is infused with real sequential and interactional import, which prompts the respective parties'starting and stopping. For example, in the following extract, the alternation is found in the silence at D:9-11, broken by simultaneous talk at D:12-13, followed by silence at D:14. In this exchange, it may be unclear whether Ava at D:7 is bringing the preceding topic/sequence to a close, or is launching an extended telling. In the end, the impasse is broken by her launching of an extended telling, although one unrelated to any of the preceding talk. (For other issues involved here, see below, note 42.)

(D) TG, 1:32-2:10

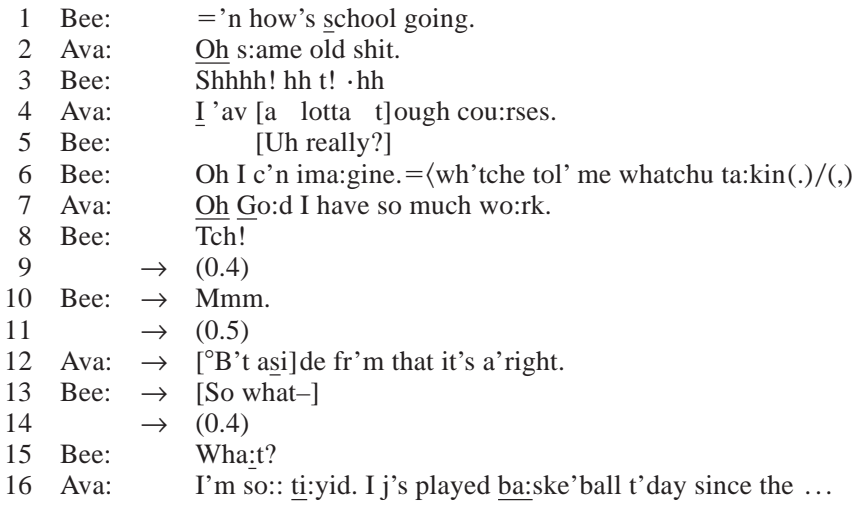

${ }^{24}$ John Heritage has underscored for me the usefulness of registering this differential responsiveness to competitive upgrade as a separate observation.

${ }^{25}$ Evidence is hard to come by, almost in the nature of the case; however, it appears that dropping out of overlap "early" can mask, as transient snafus, what are otherwise deeper investments by parties who cannot afford to display them. Pairs of interlocutors who deal with each other on a routine basis may well develop recurrent, if not routinized, trajectories of overlap resolution, with one - e.g. the employee, or the party otherwise disadvantaged relative to the other - routinely dropping out at the first sign of overlap, or persisting at most to the initial move by the other to competitive production. There can be occasions on which, with no prior design, such a person finds herself or himself moved to "stay in play" longer, continuing to talk for another beat or two after the superordinate party has "gone competitive." S/he may emerge from the interaction shaken or emboldened by what has happened, without knowing quite what it was - while the superordinate is taken aback by the unexpected display of investment, glossed in some environments as "cheekiness." At the other end of the tacit/ public spectrum (and of the bearing of status relations on overlap resolution), and illustrative of one sort of grasp of what may be involved in a spate of overlapping talk, are occurrences such as the following, taken from a news report on a public dialog on race relations in America in which President Clinton was involved: "One of the panelists, conservative policy analyst Elaine Chao, was so intent 
on getting the last word that she interrupted the President to reiterate her opposition to traditional affirmative action programs" (Los Angeles Times, July 9, 1998, p. A14). Although the journalist does not specifically mention persistence in overlap, Ms. Chao apparently persisted long enough to allow recognition of what she was doing in her talk, and it seems likely that she did so by virtue of the President's dropping out.

${ }^{26}$ To be sure, Dick is already talking, and Deb's talk could accordingly be taken as objectively being in the post-onset phase. The point suggested in the text is that, by employing compression as her adaptive resource - one deployed in PRE-onset position - she does not treat herself as already in overlap with him. The resource deployed in an overlap can be deployed reflexively to invoke, as the relevant phase, the one which it differentially normatively occupies. Similar reflexive relationships between a resource and the position in which it occurs have been described for repair initiation and the repair space (Schegloff 1992c:1326-34) and for person reference (Schegloff 1996c:450-58).

${ }^{27}$ Similar considerations may inform "heckling" (C. Goodwin \& M. Goodwin 1992a) and "byplay" (M. Goodwin 1997) which are done as side-involvements (Goffman 1979) to an ongoing (and continuing) main interaction. Doing these "parasitic" activities simultaneously - but in a subordinated, muted (often reduced to gestural) way - can get the heckle or by-play optimally close to its target or source.

${ }^{28}$ It may be useful to display one more such deployment of the resources discussed here - resources for the parties' management of overlap, and for external analysts' examination of it. In particular, it may be useful to display analysis on public data, transcribed by someone else, to obviate the possibility that the transcription and the analysis in this undertaking have been unduly symbiotic. Briefly, then, I wish to examine a brief excerpt from a well-known interview/"confrontation" between then-Vice President George Bush, when he was contending for the 1988 Republican presidential nomination, and CBS television news anchor Dan Rather. I have already written about this "interview" and about some of the overlapping talk in it (Schegloff 1989). However, the same material was separately examined by Clayman \& Whalen 1989, working from their own, independently created transcript. (In fact, there are no consequential differences between the two renderings of this stretch of talk.) Here is an extract taken from their transcript:

(E) Clayman and Whalen, 1989:256

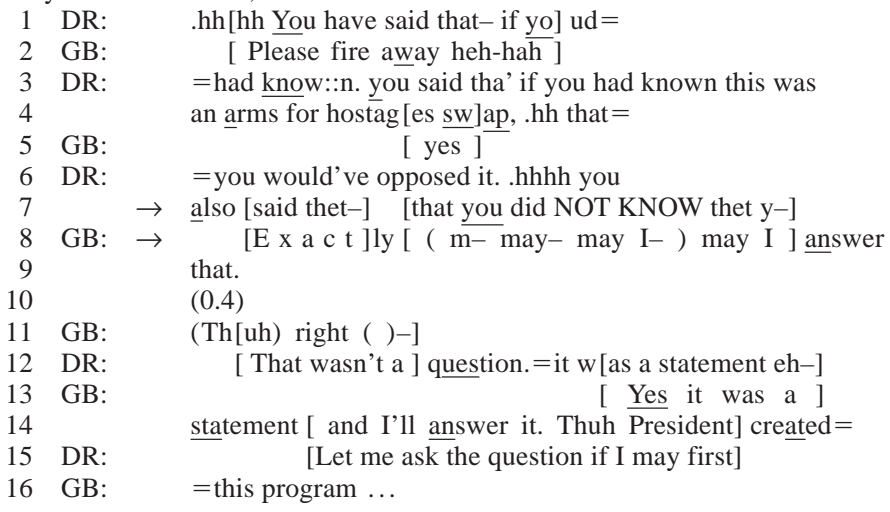

Look at lines 7-8: First, Rather cuts off his utterance-in-progress in favor of Bush's Exactly, but then he resumes by recycling the last word. When that runs into competing talk from Bush, Rather immediately, in the next beat, upgrades in volume (note the underlining of you); and when Bush in turn counters and recycles as a "response," Rather upgrades further (note the upper case of not know). When Bush recycles in response to that as well (the second may I in E:8), Rather drops out. For the place of this exchange in the interview/confrontation, cf. Clayman \& Whalen 1989 and Schegloff 1989. For additional detailed analysis of the developing trajectory of an overlap and its import, see Schegloff 1989, and the discussion in the last two sections of this paper. For an analysis of overlapping talk along these same lines in a corpus of Thai peasant talk-in-interaction, cf. Moerman 1988:19_ 
30, 188, n.15). For a detailed analysis of other American materials, in which the relative relevance of gender and interactional activities is taken up, cf. Schegloff 1997a.

${ }^{29}$ Jefferson (1996:57-58, note 11) presents additional instances of this orientation - although most of those instances involve something different from what is discussed here, namely an addition by the "persisting party" of an increment to his turn in the overlapping talk AFTER its possible completion, and after a substantial chunk of a next turn by the recipient. In effect, this amounts to persistence to RE-completion, which underscores the orientation being implemented. Note, in the text above, that Vic's turn is clearly not an ideal exemplar of this tack, including as it does several sound stretches which could be taken to display attention to the simultaneous talk.

${ }^{30}$ Jefferson 1984a shows that this is also a point at which next speakers may start a next turn in overlap with a prior one. Here we are noting that it is a point where a speaker may abandon a turnin-progress in the face of continuing overlap with another. On such "recognition points," see also Jefferson 1973.

${ }^{31}$ However, as Steve Clayman has pointed out to me, the next turn addresses it obliquely, and in a manner diversionary from its main thrust.

32 A similar outcome may be found in the exchange in ex. 5.

33 Another practice appears to embody an orientation both to speaking-to-completion and to being-sequentially-implicative. As described by Lerner 1989, speakers who find another person coming in, to anticipatorily and collaboratively complete the turn they have begun, may delay their own completion of it (i.e. withdraw from the overlap which has been engendered) and deliver their own completion after the interloper's contribution is finished. In effect this achieves the result displayed in ex. 22 - not by re-beginning the turn, but by completing it with one's own completion, thereby embodying as well a speaking-to-completion while temporarily allowing resolution of the overlap. Note that this practice has (so far) been described only for a kind of overlap which is commonly not treated as competitive at all, but as involving conditional access to the turn (see above). In this same environment, Lerner reports (p.c.) another variation from the practices described here: A recipient of a turn-so-far who enters to offer an anticipatory completion may deal with the early phases of the overlap (post-onset) not by slowing down, as described in the text above, but by speeding up, so as to produce the projected remainder of the turn before the original turn's speaker can do so to completion - evidencing the capacity either to infer or independently to articulate that completion.

${ }^{34}$ I am NOT saying that they have not noticed that another is talking, but rather that they have adopted that as a stance, which is an entirely different matter (cf. West 1979).

35 The spacing of the letters in 23:28 does not represent "speaking slowly" or "stretching out the talk," but is a graphic convention to allow proper alignment of the overlapping talk.

${ }^{36}$ Note that, in ex. 24 , Dave has registered the occurrence of overlap, but does NOT take the position that his turn-so-far has been impaired by it.

37 "Unprojected" because of the grammatical, prosodic, and pragmatic possible completion of the turn unit which precedes it (Ford \& Thompson 1996). On the vulnerability of turn-terminal address terms to overlap, see Jefferson 1973, 1984a, 1986.

38 As he did at the possible completion of Bush's first saying of it as well.

${ }^{39} \mathrm{Do}$ is replaced by can, but full re-use of reconcile marks this as "the same utterance being tried again." For both extracts from the Bush/Rather materials, the further discussion in Schegloff 1989 is relevant to the matters taken up here.

${ }^{40}$ Of course, not all repeats and partial repeats implement the action of initiating repair, nor do all instances of huh? For an account of different actions that can be implemented by these practices, see Schegloff 1997b. The remainder of this section draws heavily on research on other-initiated repair supported by the National Science Foundation under Grant No. BNS-87-20388.

${ }^{41}$ Or modification. In this instance, it might be noted that this repair initiation may also herald upcoming disagreement (see 28:6, 8), and the repair initiation provides an opportunity for the recipient to modify her utterance so as to avoid the disagreement. This account is not incompatible with one focused on the overlap-implicatedness of the repair, but the next extract examined involves no elements of disagreement at all.

${ }^{42}$ As noted earlier (note 23), this pattern of alternation of overlaps and gaps is not uncommon; it is a systematic product of the turn-taking organization - especially when, as here, the two parties to the overlap end simultaneously. It may then not be clear which of them was the "speaker of record" in the just prior turn-position; each may wait for the other to take next turn, thereby producing a 
silence. Then each may undertake to remedy the silence, thereby producing another overlap (for analysis of another such segment, cf. Schegloff 1996a:107-8).

${ }^{43}$ In a study of more than 1,350 instances of other-initiated repair, a strikingly high number (roughly one-third) of the huhs and other "open-class initiators" such as what (Drew 1997) were addressed to trouble-source turns which had been implicated in overlap. No other construction type for initiating repair appeared as much invoked for overlap aftermath. On repair initiation, cf. Schegloff et al. 1977.

${ }^{44}$ The nature of the transaction being launched is unclear; and a moment later it becomes a matter of dispute, with Vic declaring that he is not intuh selling it or giving it, and Mike protesting, Buh I din' say giving it.

${ }^{45}$ Recall that this turn served above, at the discussion of ex. 21, as an exemplar, even if an imperfect one, of a turn produced by its speaker to go to completion, taking no notice of simultaneous talk by another.

${ }^{46}$ As in ex. 28, this sequence also combines problems related to overlap with problems related to disagreement and misalignment. Vic's huh? can be understood not only as a retrieval of Rich's part in the overlap, but also as a pre-rejection of his challenge. Indeed, as the rest of the sequence shows, Rich so hears it, and each iteration of his challenge is increasingly couched in epistemically less certain terms. It should not be thought arbitrary, however, that both overlap and misalignment of other sorts co-occur in the same episode; there are many such occurrences, and for robust sequential and interactional reasons.

${ }^{47}$ Such occurrences exemplify the observations of Drew 1997 concerning the special relevance and use of "open-class repair initiators," of which huh is one, where topic shifts have precipitated problems of hearing/understanding.

${ }^{48}$ What rarely shows up in this position, as a stance toward the overlap, is an explicitly formulated complaint about it under the rubric "interruption" or any other. But that is not to say that it does not happen (cf. note 16 above, B:19). When it does, the registering of what has transpired may feature not the disruption of the implicated utterance(s) as a consequence, but the "moral" status of the simultaneous talk itself - its violative or invasive character, its impropriety. Again, when this sort of notice is taken in the aftermath of a resolution, it can have not only the form of a complaint about the other's conduct, but also the form of a notice of the openness to complaint of one's own conduct, as in the following extract (in which the transfer of some tickets is being arranged), brought to my attention by Paul Drew.

(F) Holt corpus

\begin{tabular}{|c|c|c|}
\hline Lesley: & & $\begin{array}{l}\text {... he dzn't normally go on a Fri:day see it's just c'z these } \\
\text { Italian: fellows've come ovah } . \overline{h h}[\mathrm{~h} \text { an }\end{array}$ \\
\hline Hal: & & [ $\underline{\text { Oh }}$ ee Have they"y. $=$ \\
\hline Lesley: & & $=\mathrm{iYe}[: \mathrm{s}$. \\
\hline Hal: & & [Yeh \\
\hline Lesley: & $\rightarrow$ & .hhh And so that's why we're [a bit- \\
\hline Hal: & $\rightarrow$ & $(0.3) \quad[$ (But) - \\
\hline Lesley: & & $-\mathrm{hh}$ \\
\hline Hal: & $\rightarrow$ & $\begin{array}{l}\text { Ah- }(0.2) \text { Oh interruptin' you I wz g'nna say you could } \downarrow \text { leave } \\
\text { it'n I mean if you wanted to come you could j's pay me when } \\
\text { you ca:me. }\end{array}$ \\
\hline
\end{tabular}

Here we stand at the boundary between overlap and its resolution as an event in talk-in-interaction, on the one hand, and "interruption" as a distinctive act, on the other. Because "interruption" appears to involve other orders of consideration (such as "complainability"), pursuit of this discussion is reserved for another occasion.

${ }^{49}$ It will be useful subsequently to explore the bearing of the treatment accorded to simultaneous talk here on the main thrust of other types of treatments, largely of "interruption," which have figured centrally in the discussions of recent years; but such an undertaking is reserved to a separate paper.

${ }^{50}$ In SSJ, we called them "rules," but for some readers this has been troubling, and for others a possible source of misunderstanding (like Searle 1992; cf. my response in Schegloff 1992); so I now offer "practices" as an alternative term.

${ }^{51}$ See the related discussion in Wilson \& Zimmerman 1986. 
52 Here I am both agreeing and disagreeing with the conclusions of Jefferson 1983. On the one hand, Jefferson ends her exploration of overlap resolution by noting "the absence of generic rules for deciding who shall drop out and who shall proceed" (1983:33) - a conclusion that I take to converge with the finding in the text above, that the overlap resolution device "does not specify who the "winner' is." On the other hand, she takes "the possible range of devices deployed within overlap to seek to resolve it" to evidence the ABSENCE of a general solution. I take it to CONSTITUTE a general solution of a procedural sort. The turn-taking organization as a whole constitutes a procedural solution to the ordering problem in the distribution of turns in conversation, and to the size-control problem in their production, not by stipulating substantive outcomes, but by providing procedural resources - practices - by which the parties can fashion solutions suited to the specifics of their circumstances; so also, the practices of overlap resolution provide tools for fashioning solutions or resolutions, rather than pre-specified outcomes or classes of outcomes. In her article on overlap onset, Jefferson (1984a:16) articulates a closely related position: "Roughly, although there is a general rule, 'do not interrupt' ... there appears to be no rule which provides for who should stop and who should proceed. The working out of this matter seems to be done along interactional/contextual guidelines rather than by following some simple rule for "overlap resolution." The present article has offered an account of some systematic resources and deployment practices by reference to which the operation of such guidelines can be specified (see Local \& Kelly 1986).

53 This was suggested by finding that the rush-through - as a speaker's practice for retaining the turn, while approaching the transition space - is in effect identical with the compression of pace deployed in the pre-onset phase of the overlap resolution device; cf. note 18 above.

${ }^{54}$ Of course, noting this possibility is just the start of the analysis, not its end. One can then return to the tape for closer examination of the conduct of others which may have prompted in the speaker the suspicion that another was about to start, and closer examination of the speaker's conduct for other evidence that such a suspicion was entertained.

\section{R EFERENCES}

Atkinson, J. Maxwell (1984). Public speaking and audience responses: Some techniques for inviting applause. In J. M. Atkinson \& J. Heritage (eds.), Structures of social action, 370-410. Cambridge \& New York: Cambridge University Press.

Brown, Penelope (1996). The conversational context for language acquisition: A Tzeltal (Mayan) case study. Plenary Address, Fifth International Conference, International Pragmatics Association, Mexico City, July.

Clayman, Steven (1993). Booing: The anatomy of a disaffiliative response. American Sociological Review 58:110-30.

, \& Whalen, Jack (1989). When the medium becomes the message: The case of the RatherBush encounter. Research on Language and Social Interaction 22:241-72.

Coates, Jennifer (1988). Gossip revisited: Language in all-female groups. In J. Coates \& Deborah Cameron (eds.), Women in their speech communities: New perspectives on language and sex, 94-122. London: Longman.

Couper-Kuhlen, Elizabeth (1993). English speech rhythm: Form and function in everyday verbal interaction. Amsterdam: Benjamins.

\& Selting, Margret (1996), eds. Prosody in conversation: Interactional studies. Cambridge \& New York: Cambridge University Press.

Drew, Paul (1997). "Open" class repair initiators in response to sequential sources of troubles in conversation. Journal of Pragmatics 28:69-101.

Duncan, Starkey, Jr. (1972). Some signals and rules for taking speaking turns in conversations. Journal of Personality and Social Psychology 23:283-92.

(1974). On the structure of speaker-auditor interaction during speaking turns. Language in Society 2:161-80.

\& Fiske, Donald W. (1977). Face-to-face interaction: Research, methods, and theory. Hillsdale, $\mathrm{NJ}$ : Erlbaum.

Duranti, Alessandro (1997). Polyphonic discourse: Overlapping in Samoan ceremonial greetings. Text 17:349-81. 
Edelsky, Carole (1981). Who's got the floor? Language in Society 10:383-421.

Egbert, Maria (1993). Schisming: The transformation from a single conversation to multiple conversations. Dissertation, Department of Applied Linguistics, University of California, Los Angeles. (1997). Schisming: The collaborative transformation from a single conversation to multiple conversations. Research on Language and Social Interaction 30:1-51.

Erickson, Frederick, \& Shultz, Jeffrey (1982). The counselor as gatekeeper: Social interaction in interviews. New York: Academic Press.

Ford, Cecilia E., \& Thompson, Sandra A. (1996). Interactional units in conversation: Syntactic, intonational, and pragmatic resources for the management of turns. In Ochs et al. (eds.), 134-84.

French, Peter, \& Local, John K. (1983). Turn-competitive incomings. Journal of Pragmatics 7:17-38.

Goffman, Erving (1955). On face-work: An analysis of ritual elements in social interaction. Psychiatry 18:213-31.

(1979). Footing. Semiotica 25:1-29. [Reprinted in E. Goffman, Forms of talk, 124-59. Philadelphia: University of Pennsylvania Press, 1981.]

Goodwin, Charles (1980). Restarts, pauses, and the achievement of mutual gaze at turn-beginning. Sociological Inquiry 50:272-302.

(1981). Conversational organization: Interaction between speakers and hearers. New York: Academic Press.

(1986). Between and within: Alternative treatments of continuers and assessments. Human Studies 9:205-17.

; \& Goodwin, Marjorie Harness (1987). Concurrent operations on talk: Notes on the interactive organization of assessments. IPrA Papers in Pragmatics 1:1-52.

(1992a). Context, activity and participation. In Peter Auer \& Aldo di Luzio (eds.), The contextualization of language, 77-99. Amsterdam: Benjamins.

(1992b). Assessments and the construction of context. In Alessandro Duranti \& C. Goodwin (eds.), Rethinking context: Language as an interactive phenomenon, 151-89. Cambridge $\&$ New York: Cambridge University Press.

Goodwin, Marjorie Harness (1990). He-said-she-said: Talk as social organization among black children. Bloomington: Indiana University Press.

(1997). By-play: Negotiating evaluation in story-telling. In Gregory R. Guy et al. (eds.),

Towards a social science of language: Papers in honor of William Labov, II: Social interaction and discourse structures, 77-102. Amsterdam: Benjamins.

\& Goodwin, Charles (1986). Gesture and coparticipation in the activity of searching for a word. Semiotica 62:51-75.

Greenberg, Steven (1997). On the origins of speech intelligibility in the real world. Proceedings of the ESCA Workshop on Robust Speech Recognition for Unknown Communication Channels, 23-32. Pont-à-Mousson, France: European Speech Communication Association.

Hayden, Robert M. (1987). Turn-taking, overlap, and the task at hand: Ordering speaking turns in legal settings. American Ethnologist 14:251-70.

Heritage, John C., \& Greatbatch, David (1986). Generating applause: A study of rhetoric and response at party political conferences. American Journal of Sociology 92:110-157.

Hopper, Robert (1992). Telephone conversation. Bloomington: Indiana University Press.

Jefferson, Gail (1973). A case of precision timing in ordinary conversation: Overlapped tag-positioned address terms in closing sequences. Semiotica 9:47-96.

(1979). A technique for inviting laughter and its subsequent acceptance/declination. In George Psathas (ed.), Everyday language: Studies in ethnomethodology, 79-96. New York: Irvington.

(1983). On a failed hypothesis: "Conjunctionals" as overlap-vulnerable. In her Two explorations of the organization of overlapping talk in conversation (Tilburg papers in language and literature, 28). Tilburg, The Netherlands: Tilburg University.

(1984a). Notes on some orderlinesses of overlap onset. In Valentina D'Urso \& Paolo Leonardi (eds.), Discourse analysis and natural rhetorics, 11-38. Padova: CLEUP.

(1984b). Notes on a systematic deployment of the acknowledgment tokens "Yeah" and "Mm hm". Papers in Linguistics 17:197-216.

(1985). An exercise in the transcription and analysis of laughter. In Teun A. van Dijk (ed.), Handbook of discourse analysis, 3:25-34. New York: Academic Press.

(1986). Notes on "latency" in overlap onset. Human Studies 9:153-83. 
(1990). List construction as a task and interactional resource. In George Psathas (ed.), Interaction competence, 63-92. Washington, DC: International Institute for Ethnomethodology and Conversation Analysis; University Press of America.

(1996). On the poetics of ordinary conversation. Text and Performance Quarterly 16:1-61. , \& Schegloff, Emanuel A. (1975). Sketch: Some orderly aspects of overlap onset in natural conversation. Paper presented at the 74th Annual Meeting of the American Anthropological Association, San Francisco.

Lerner, Gene Howard (1987). Collaborative turn sequences: Sentence construction and social action. Dissertation, Psychology, University of California at Irvine.

(1989). Notes on overlap management in conversation: The case of delayed completion. Western Journal of Speech Communication 53:167-77.

(1991). On the syntax of sentences-in-progress. Language in Society 20:441-458.

(1996). On the "semi-permeable" character of grammatical units in conversation: Conditional entry into the turn space of another speaker. In Ochs et al. (eds.), 238-76.

(1999a). Turn-sharing: The choral co-production of talk in interaction. In Cecilia A. Ford, Barbara A. Fox, and Sandra A. Thompson (eds.), The language of turn and sequence, to appear. Oxford \& New York: Oxford University Press.

(1999b). ed. Conversation analysis: Studies from the first generation. Washington, DC: University Press of America, to appear.

Local, John, \& Kelly, John (1986). Projection and 'silences': Notes on phonetic and conversational structure. Human Studies 9:185-204.

Local, John, \& Wooton, Anthony (1995). Interactional and phonetic aspects of immediate echolalia in autism: A case study. Clinical Linguistics and Phonetics 9:155-94.

Moerman, Michael (1977). The preference for self-correction in a Tai conversational corpus. Language 53:872-82.

(1988). Talking culture: Ethnography and conversation analysis. Philadelphia: University of Pennsylvania Press.

Ochs, Elinor; Schegloff, Emanuel A.; \& Thompson, Sandra (1996). eds. Interaction and grammar. Cambridge \& New York: Cambridge University Press.

Payne, Sarah, \& Wells, Bill (1999). Prosodic aspects of interruptive and non-interruptive overlap. Language and Speech 41, to appear.

Philips, Susan U. (1976). Some sources of cultural variability in the regulation of talk. Language in Society 5:81-96.

Reisman, Karl (1974). Contrapuntual conversations in an Antiguan village. In Richard Bauman \& Joel Sherzer (eds.), Explorations in the ethnography of speaking, 110-24. Cambridge \& New York: Cambridge University Press.

Sacks, Harvey (1992). Lectures on conversation. 2 vols. Ed. by Gail Jefferson, with introductions by Emanuel A. Schegloff. Oxford: Blackwell. [Lectures given in 1967.]

; Schegloff, Emanuel A.; \& Jefferson, Gail (1974). A simplest systematics for the organization of turn-taking for conversation. Language 50:696-735.

Schegloff, Emanuel A. (1968). Sequencing in conversational openings. American Anthropologist 70:1075-95.

(1979). The relevance of repair for syntax-for-conversation. In Talmy Givon (ed.), Syntax and semantics, 12: Discourse and syntax, 261-88. New York: Academic Press. 50:104-52.

(1980). Preliminaries to preliminaries: "Can I ask you a question." Sociological Inquiry

(1982). Discourse as an interactional achievement: Some uses of "uh huh" and other things that come between sentences. In Deborah Tannen (ed.), Analyzing discourse: Text and talk, Georgetown University Roundtable on Languages and Linguistics 1981, 71-93. Washington, DC: Georgetown University Press.

(1987a). Recycled turn beginnings: A precise repair mechanism in conversation's turn-taking organisation. In Graham Button \& John R. E. Lee (eds.), Talk and social organisation, 70-85. Clevedon, UK: Multilingual Matters. [Originally written in 1973.]

(1987b). Between macro and micro: Contexts and other connections. In Jeffrey Alexander et al. (eds.), The Micro-Macro Link, 207-34. Berkeley: University of California Press.

(1988). Goffman and the analysis of conversation. In Paul Drew \& Anthony Wootton (eds.), Erving Goffman: Exploring the interaction order, 89-135. Cambridge: Polity Press. 
(1989). From interview to confrontation: Observations on the Bush/Rather encounter. Research on Language and Social Interaction 22:215-40.

(1992a). To Searle on conversation: A note in return. In John R. Searle et al., (On) Searle on conversation, 113-28. Amsterdam: Benjamins.

(1992b). Repair after next turn: The last structurally provided place for the defence of intersubjectivity in conversation. American Journal of Sociology 95:1295-345.

(1995). Parties and talking together: Two ways in which numbers are significant for talk-ininteraction. In Paul ten Have \& George Psathas (eds.), Situated order: Studies in social organization and embodied activities, 31-42. Washington, DC: University Press of America.

(1996a). Turn organization: One intersection of grammar and interaction. In Elinor Ochs et al. (eds.), 52-133.

(1996b). Confirming allusions: toward an empirical account of action. American Journal of Sociology 104:161-216.

(1996c). Some practices for referring to persons in talk-in-interaction: A partial sketch of a systematics. In Barbara A. Fox (ed.), Studies in anaphora, 437-85. Amsterdam: Benjamins.

(1997a). Whose text? Whose context? Discourse \& Society 8:165-87.

(1997b). Practices and actions: Boundary cases of other-initiated repair. Discourse Processes 23:499-545.

, Jefferson, Gail; \& Sacks, Harvey (1977). The preference for self-correction in the organization of repair in conversation. Language 53:361-82.

Searle, John R. (1992). On conversation. In Searle et al., (On) Searle on conversation, 7-29. Amsterdam: Benjamin.

Segui, Juan; Dupoux, Emanuel; \& Mehler, Jacques (1990). The role of the syllable in speech segmentation, phoneme identification, and lexical access. In Gerry Altmann (ed.), Cognitive models of speech processing: Psycholinguistic and computational perspectives, 263-80. Cambridge, MA: MIT Press.

Sidnell, Jack (1998). How much "culture" in interaction? Interruption and turn-taking in Caribbean English Creole conversation. MS.

Smith-Lovin, Lynn, \& Brody, Charles (1989). Interruptions in group discussions: The effects of gender and group composition. American Sociological Review 54:424-35.

Tannen, Deborah (1983). When is an overlap not an interruption? One component of conversational style. In Robert J. DiPietro et al. (eds.), The First Delaware Symposium on Language Studies, 119-29. Newark, DE: University of Delaware Press.

West, Candace (1979). Against our will: Male interruptions of females in cross-sex conversation. Annals of the New York Academy of Sciences 327:81-97.

Wilson, Thomas P., \& Zimmerman, Don H. (1986). The structure of silence between turns in twoparty conversation. Discourse Processes 9:375-90.

A P P E N D I X 1

\section{Transcript Symbols}

(Adapted from Ochs et al. 1996:461-65)

\section{Temporal and sequential relationships}

A. Overlapping or simultaneous talk is indicated in a variety of ways. [ Separate left square brackets, one above the other on two successive lines [ with utterances by different speakers, indicates a point of overlap onset, whether at the start of an utterance or later.

] Separate right square brackets, one above the other on two successive lines ] with utterances by different speakers indicates a point at which two overlapping utterances both end, where one ends while the other continues, or simultaneous moments in overlaps which continue. 
So, in the following, Bee's Uh really? overlaps Ava's talk starting at $a$ and ending at the $t$ of tough.

Ava: I 'av [a lotta t] ough cou:rses.

Bee: [Uh really?]

$=$ B. Equal signs ordinarily come in pairs - one at the end of a line, and another at the start of the next line or one shortly thereafter. They are used to indicate two things:

(1) If the two lines connected by the equal signs are by the same speaker, then there was a single, continuous utterance with no break or pause, which was broken up in order to accommodate the placement of overlapping talk. For example, in the following extract,

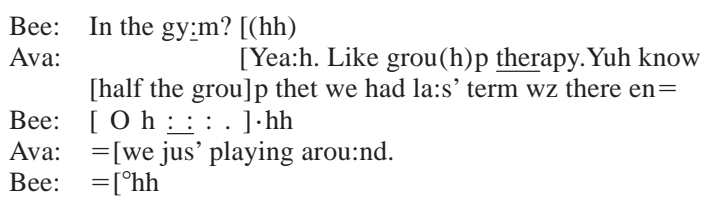

Ava's talk is continuous, but room has been made for Bee's overlapping talk (the $O h$ ).

(2) If the lines connected by two equal signs are by different speakers, then the second followed the first with no discernable silence between them, or was "latched" to it.

(0.5) C. Numbers in parentheses indicate silence, represented in tenths of a second; what is given here in the left margin indicates 0.5 seconds of silence. Silences may be marked either within an utterance or between utterances, as in the two excerpts below:
(a) Bee: ·hh Uh::, (0.3) I don'know I guess she's aw- she's awright she went to thee uh:: hhospital again tihda:y,
(b) Bee: Tch! .hh So uh I don't kno:w,

(.) D. A dot in parentheses indicates a "micropause," hearable but not readily measurable without instrumentation; ordinarily less than 0.2 of a second.

II. Aspects of speech delivery, including aspects of intonation

A. The punctuation marks are NOT used grammatically, but to indicate - intonation. The period indicates a falling, or final, intonation contour, not

? necessarily the end of a sentence. Similarly, a question mark indicates rising , intonation, not necessarily a question, and a comma indicates "continuing" $i$ intonation, not necessarily a clause boundary. The inverted question mark $(i)$ is used to indicate a rise stronger than a comma but weaker than a question mark. 
: : $\quad$ B. Colons are used to indicate the prolongation or stretching of the sound just preceding them. The more colons, the longer the stretching. On the other hand, graphically stretching a word on the page by inserting blank spaces between the letters does NOT necessarily indicate how it was pronounced; it is used to allow alignment with overlapping talk:

Bee: Tch! (M'n)/(En) they can't delay much lo:nguh they [jus' wannid] uh- ${ }^{\circ} \mathrm{hhh}=$

Ava: [ $\mathrm{O}$ h : : .]

Bee: =yihknow have anothuh consulta:tion,

Ava: Ri::ght.

Bee: En then deci::de.

The word ri::ght in Ava's second turn, or deci::de in Bee's third are more stretched than oh: in Ava's first turn, even though oh: appears to occupy more space. But $o h$ has only one colon, and the others have two; oh: has been spaced out so that its brackets will align with the talk in Bee's (jus'wannid) turn with which it is in overlap.

C. A hyphen after a word or part of a word indicates a cut-off or self-interruption, often done with a glottal or dental stop.

word D. Underlining is used to indicate some form of stress or emphasis, either by increased loudness or higher pitch. The more underlining, the greater the emphasis.

word Therefore, underlining sometimes is placed under the first letter or two of a word, rather than under the letters which are actually raised in pitch or volume.

WOrd Especially loud talk may be indicated by upper case; again, the louder, the more letters in upper case. And in extreme cases, upper case may be underlined.

$\circ \quad$ E. The degree sign indicates that the talk following it was mark○ edly quiet or soft. When there are two degree signs, the talk beween them is markedly softer than the talk around it.

F. Combinations of underlining and colons are used to indicate intonation contours:

_: $\quad$ If the letter(s) preceding a colon is/are underlined, then there is an "inflected" FALLING intonation contour on the vowel (you can hear the pitch turn downward).

$\therefore \quad$ If a colon is itself underlined, then there is an inflected RISING intonation contour on the vowel (i.e., you can hear the pitch turn upward): 


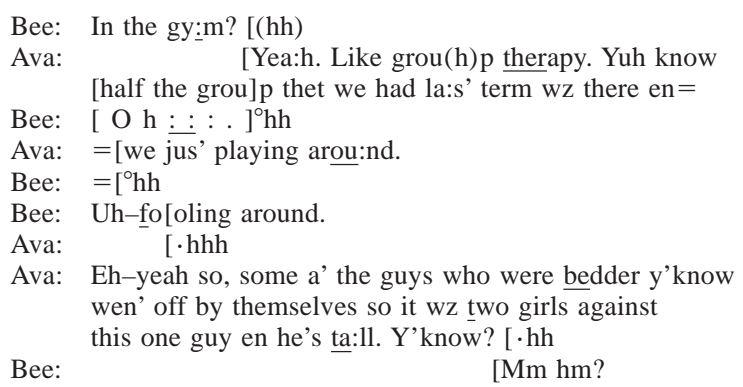

Thus the Oh:... in Bee's second turn has an upward inflection while it is being stretched (even though it ends with falling intonation, as indicated by the period). On the other hand, ta: $l l$ at the end of Ava's last turn is inflected downward ("bends downward," so to speak) over and above its "period intonation."

G. The up and down arrows mark sharper rises or falls in pitch than would be be indicated by combinations of colons and underlining, or they may mark a whole shift, or resetting, of the pitch register at which the talk is being produced.
$>\quad$ H. The combination of "more than" and "less than" symbols in- dicates that the talk between them is compressed or rushed. Used in the reverse order, they can indicate that a stretch of talk is markedly slowed or drawn out. The "less than" symbol by itself indicates that the im- mediately following talk is "jump-started," i.e. sounds like it starts with a rush.

hhh I. Hearable aspiration is shown where it occurs in the talk by the letter $h$ - the more $h$ 's, the more aspiration. The aspiration may represent (hh) breathing, laughter, etc. If it occurs inside the boundaries of a word, it may be enclosed in parentheses in order to set it apart from the sounds of the word (as in the utterance below). If the aspiration is an inhala- hh tion, it is shown with a dot before it (usually a raised dot).

Bee: [Ba::]sk(h)etb(h)a(h)ll? (h)( $\cdot$ Whe(h)re.)

III. Other markings

(( )) A. Double parentheses are used to mark transcriber's descriptions of events, rather than representations of them: ((cough)), ((sniff)), ((telephone rings)), ((footsteps)), ((whispered)), ((pause)), and the like.

(word) B. When all or part of an utterance is in parentheses, or the speaker identification is, this indicates uncertainty on the transcriber's part, but represents a likely possibility. 
( ) Empty parentheses indicate that something is being said, but no hearing (or, in some cases, speaker identification) can be achieved.

(try 1)/ C. In some transcript excerpts, two parentheses may be printed, (try 2) separated by a single oblique or slash; these represent alternative hearings of the same strip of talk.

Bee: ${ }^{\circ}(\mathrm{Bu}: \mathrm{t}$. $)=/{ }^{\circ}($ Goo: $:$. $)=$

Here the degree marks show that the utterance is very soft. The transcript remains indeterminate between Bu::t. and Goo:d. Each is in parentheses and they are separated by a slash.

The core of this set of notational conventions was first developed by Gail Jefferson. It continues to evolve and adapt both to the work of analysis, the developing skill of transcribers, and changes in technology. Not all symbols have been included here, and some symbols in some data sources are not used systematically or consistently.

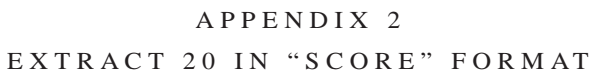

Anne: Every six months I wen'in fih shoes. 'n I had- I must've had about, (0.5) a hundred pairs (a) shoes.

Deb: Really mother $=$ you spent-

(1.0)

Dick: you know [wha:t, ]

Deb: [Boy we]re you:: $\mathrm{w}-[\mathrm{w}$ a s t e d ]

Dick: $(0.8)$ [(you know) sh-] exaggerated slightly.

Dick: Y'[know what- y'know][( ) $]$

Deb: [w h a t a w a s][t e r you ]were ]

Anne: [D O N'T S]A Y that I'm ex] a- just say I'm a liar.

Dick: Y'know what, yer [g r a n d m o th e r-]

Deb: [ $\quad$ 'ts not a question〈] of [ly:ing 〈'ts a question of being- >] Dick: [yer GRANDMOTHER IS A CENTI]PE:DE, = $=$ that's why $-\operatorname{sh}[\mathrm{e}$ esstuh hev a khundred pairs of shoes.

Deb: $\quad\left[\left(y^{\prime}\right.\right.$ gi- $)$

Deb: a'hhu:::mm.

Dick: uhh! ${ }^{\circ}$ huh huh hee hee [hee

Deb: [Boy ma, you really: (0.5) I'm ama:zed. 